\title{
Experimental investigation of drag models for the two fluid simulation of Geldart group A powders
}

X. Lu ${ }^{1}$, D. J. Holland ${ }^{* 2}$

(*) Corresponding author. Email: daniel.holland@canterbury.ac.nz. Tel: +64-3-364-2987 ext 7274

(1) Department of Chemical Engineering and Biotechnology, University of Cambridge, New Museums Site, Pembroke Street, Cambridge CB2 3RA, UK.

(2) Department of Chemical and Process Engineering, University of Canterbury, Christchurch, New Zealand 


\begin{abstract}
Electrical capacitance tomography and magnetic resonance imaging were used to investigate two drag models used when simulating Geldart group A powders with the two fluid model. Experiments were performed using cylindrical fluidised beds $50 \mathrm{~mm}$ in diameter with a silicaalumina catalyst support particle of diameter $63 \mu \mathrm{m}$. A dense phase, bubbling fluidised bed and a dilute phase, circulating fluidised bed were studied. Simulations were performed using the open source software MFIX. The two drag models considered were the revised Gibilaro model and the Energy Minimisation Multiscale model. Both of these models have previously been shown to be effective at describing the fluidisation of Geldart group A powders. The comparison of the simulations with experimental measurements presented here demonstrates that the revised Gibilaro model can be used to predict the voidage and particle velocity distribution in the dense fluidised bed with a high degree of accuracy, however when used to simulate the circulating fluidised bed it underestimates the solids circulation rate by approximately a factor of 4 . The Energy Minimisation Multiscale drag model is able to predict the circulating fluidised bed solids circulation rate to within about $50 \%$, however it does not predict the correct voidage distribution in the dense fluidised bed. These results indicate that neither model is able to predict the fluidisation behaviour across the entire range of fluidisation conditions.
\end{abstract}

Keywords: fluidised bed; two fluid model; magnetic resonance imaging; electrical capacitance tomography 


\section{Introduction}

Computational fluid dynamics (CFD) is increasingly being used to design and optimize chemical processes, including fluidised beds. CFD simulations provide estimates of the complete dynamics of the fluidisation process, including the gas and solids velocity, voidage, and heat and mass transfer. The simulations can potentially be used for virtual experiments and therefore facilitate better scale-up of industrial fluidised beds. The most commonly used CFD models for fluidised bed applications are the two fluid method (TFM) [1], and the discrete element method (DEM)[2]. Of these, only the TFM can be used to simulate industrial scale FBs in a reasonable simulation time, so it is widely considered the most promising approach for aiding the design and operation of fluidised beds. However, the TFM requires the use of closure models to describe, for example, collisions in the particle phase and the interaction of the fluid and particle phases. In order to use these models to predict the performance of industrial reactors it is essential that these closure laws are validated. This work focuses on the validation of TFM simulations of the fluidisation of Geldart's group A particles using detailed experimental measurements.

The TFM has been shown to successfully predict hydrodynamic phenomena when simulating Geldart's group B and D powders in dense fluidised beds. For example, in dense fluidised beds of coarse particles (particle diameter, $d_{p}=200-600 \mu \mathrm{m}$ ), the TFM has been shown to provide at least qualitative agreement with experimental measurements of the bubbles, bed expansion, voidage distribution, solids velocity distribution and pressure [3-5]. However, it has proven difficult to apply the TFM to describe the hydrodynamic behaviour of Geldart group A particles, which are characterized by their fine particle size [6-14]. [6-14]The key findings of these studies are (1) the bed expansion of fine particles in a fluidised bed is over-predicted by as much as $70 \%$ and (2) the solid circulation rate is overestimated by more than $200 \%$. Two, related, hypotheses have been proposed to explain the failure of the TFM for Geldart's group A particles: clustering of particles and coarse meshes.

Clustering of particles refers to the formation of localised regions or strands of high concentrations of particles. Seville et al. [15] showed that spherical particles of diameter of order 
$100 \mu \mathrm{m}$ should exhibit inter-particle van der Waals forces equal to their single particle weight and hence concluded that clustering must be significant for $\mathrm{d}_{\mathrm{p}}<100 \mu \mathrm{m}$. Particle clustering can also arise from hydrodynamic effects alone (i.e. in the absence of inter-particle cohesive forces) [16]. Mostoufi and Chaouki [17] demonstrated the existence of clusters in dense fluidised bed of sands and FCC particles by analyzing the time-position data of a tracer in radioactive particle tracking experiments. Li et al. [18] used two optical fibre probes to measure the cluster size distribution in a fast fluidised bed of FCC particles. Holland et al. [19] estimated the cluster size to be between $250 \mu \mathrm{m}$ and $500 \mu \mathrm{m}$ using MRI measurements of the particle velocity in a coreannular fluidised bed. Lettieri et al. [20] calculated effective cluster diameters in the range of 200 $\mu \mathrm{m}$ to $474 \mu \mathrm{m}$ for FCC catalysts with diameters from $49-71 \mu \mathrm{m}$. Thus, there is broad agreement that clustering effects are significant when Geldart group A particles are fluidised.

The second explanation for the poor performance of the TFM when simulating Geldart group A particles is that the mesh size is too large, and hence fine structures in the flow are not adequately modelled. The volume averaging approach used in the TFM assumes that the voidage distribution within a single CFD cell is uniform. For this approach to be valid, a separation of scales between the particle size and the size of the finest structures in the flow must exist. Typically, this is interpreted as saying that the smallest mesh size should be $\sim 5$ times the particle diameter; the upper limit on mesh size is not clear. Owing to the decrease in simulation time and memory requirements, most researchers choose a mesh size that is coarse $\left(\sim 100 d_{\mathrm{p}}\right)$ when simulating fine particles compared to that used when simulating group B/D particles $\left(\sim 10 d_{\mathrm{p}}\right)$. Thus, in reality, there will be a distribution of particles within the cell, as illustrated in Figure 1. Wang et al. [11] indicated that if a sufficiently fine mesh size $\left(\sim 5 d_{p}\right)$ and small time step is used, the TFM prediction of the bed expansion approaches the experimentally measured values without any artificial modifications. Further, through DEM simulations they show that simulation results are strongly influenced by the size of the mesh, and therefore attribute the failure of the TFM to a lack of consideration of sub-grid scale heterogeneous structure [21]. However, it is impracticable to simulate large pilot and industrial scale reactors with a mesh size of $<0.5 \mathrm{~mm}$ owing to the long simulation time and high requirements for hardware. On the other hand, even if a very fine mesh is used, the TFM might not describe the fluidisation of fine particles correctly. For example, although Wang et al. [11] showed the correct bed expansion by using a fine mesh $(0.2 \mathrm{~mm})$ for FCC particles $\left(d_{p}=75 \mu \mathrm{m}\right)$, minimum bubbling is 
underestimated. Benyahia [22] used a fine mesh $\left(1 \mathrm{~mm}, \sim 18 d_{p}\right)$ to simulate a circulating fluidised bed with the Wen-Yu drag model. The predictions of solids flux improved as the mesh size was refined but the minimum solid flux estimated was still $130 \mathrm{~kg} \mathrm{~m}^{-2} \mathrm{~s}^{-1}$, much higher than the experimental value of $14.3 \mathrm{~kg} \mathrm{~m}^{-2} \mathrm{~s}^{-1}$. Thus, although a fine mesh helps improve TFM simulations, it does not appear to be sufficient to describe the fluidisation of fine particles completely.

The methods for resolving this problem are to treat the sub-grid structures as clusters only, to treat the sub-grid structures as clusters and dispersed particles [14] or to use the filter method whereby simulations with a fine mesh are used to derive the corresponding drag for a coarse mesh [10]. McKeen and Pugsley [6] found that by multiplying the drag force calculated by Gibilaro's gas-solids drag law [23] by a factor of 0.2 to 0.3 , TFM simulations were able to adequately predict the bed expansion observed experimentally. The reduction in drag corresponds approximately to an effective particle diameter in the range of 135 - $170 \mu \mathrm{m}$ for FCC particles of actual mean diameter of $75 \mu \mathrm{m}$. They suggest these findings support the argument that cohesive inter-particle forces lead to agglomeration of FCC catalyst powder and significantly affect the fluidisation quality. Li et al. [24] modified the standard Gidaspow drag model, using insights from DEM simulations and experiments by dividing the drag law into four regions according to the local voidage. Li's model was shown to provide accurate estimates of the voidage profile in a circulating fluidised bed. Wang et al. [14] used the energy minimization multi-scale (EMMS) model as the sub-grid scale model with clusters (dense phase) and dispersed particles (dilute phase) for the effective inter-phase drag force and simulated dense fluidisation of FCC particles with coarse meshes. The EMMS model was designed to characterize the presence of clusters and dilute gas-solids flow within a riser [25]. It was later adapted for use with TFM simulations and is now well established for simulations of the fluidisation of Geldart's group A particles in the riser of circulating fluidised beds [26] and other related models are becoming available [27]. A similar approach has been used to produce a bubble-structure based model dedicated to the simulation of dense fluidised beds [28]. An alternative approach to capture the sub-grid scale structure is to simulate the flow using a fine grid and then use these simulations to derive a filtered drag model that can be used to simulate industrial systems with a "coarse" mesh [10]. Several studies have explored the different drag models available [29-31], however the comparison has previously been limited to a specific fluidisation regime. It is not 
clear whether any of these modified drag models are applicable to the entire range of fluidisation conditions that might be encountered, nor whether they provide a true representation of the fluidisation dynamics. There is therefore a need to present detailed experimental studies to validate the predictions of TFM simulations.

The most common experimental measurement of a fluidised bed is the pressure drop, which can be used to infer the axial voidage distribution [32,33]. However, this method is only applicable when the wall friction and particle acceleration in the bed are neglected with the static head of particles [34], and therefore should only be considered in the top section of the riser [35]. Other common techniques used to investigate fluidised beds include, optical fibre probes, capacitance probes and momentum probes. These provide only point wise measurements of the fluidisation dynamics and are intrusive. Non-intrusive, tomographic imaging techniques have been developed in recent years, such as X-ray Computerized Tomography (CT), $\gamma$-ray CT, magnetic resonance imaging (MRI) and electrical capacitance tomography (ECT) [36-40]. MRI is a tomographic technique that permits direct quantitative measurements of the voidage and velocity of particles in fluidised beds $[19,41,42]$. However, measurements are restricted to the laboratory environment and non-metallic systems, and are particularly challenging when particles can leave the magnetic field [42]. ECT is another non-invasive technique that is more readily applied to fast moving processes, such as a CFB. ECT can be used on bubbling fluidised beds to measure the bubble shape and bubble frequency, and fluidisation regime [43], or on CFBs to measure the distribution of solids and detect choking [39].

This work explores the use of MRI and ECT to validate TFM simulations of gas-solid fluidised beds of Geldart's group A particles. It is well established that conventional drag models are ineffective for simulations of Geldart's group A powders, therefore two sub-grid drag models are considered: the modified Gibilaro model [6] and a model based on the EMMS criterion [44], which for the purpose of this paper will be referred to as the EMMS model. These models have previously been shown to be effective for simulating bubbling and circulating fluidised beds, respectively. Here both models are applied to the simulation of both bubbling and circulating fluidised beds and the results are compared with MRI and ECT measurements on the same systems. 


\section{Experimental}

\subsection{Bubbling Fluidised bed}

The bubbling fluidised bed measurements come from earlier publications [19,45]. Additional pressure and expanded bed height measurements were obtained on the same system as part of the present study. The experiments were performed in a Perspex tube with internal diameter of $50 \mathrm{~mm}$ as illustrated in Figure 2(a). A sintered glass plate (40 mm in diameter) with $100-160$ $\mu \mathrm{m}$ pores was used as the gas distributor. The air was supplied by a gas compressor and the flow rate was controlled by a rotameter. The particles are silica-alumina catalyst support and were doped with a $\mathrm{GdCl}_{3}$ solution to provide a signal for the MRI. The initial packed bed height was $120 \mathrm{~mm}$. In order to keep the water content of the particles constant, the particles were fluidised using humid air during the experiments and for $4 \mathrm{hr}$ before the experiments began. The physical properties of the particles are listed in Table 1 and were obtained from experimental measurements, as has been reported previously [19].

MRI experiments were carried out on a Bruker DMX 200 spectrometer operating at a proton $\left({ }^{1} \mathrm{H}\right)$ resonance frequency of 199.7 MHz. Full experimental details are described elsewhere[19,45].

\subsection{Circulating Fluidised Bed}

The circulating fluidised bed is made from Perspex tube as shown in Figure 2(b). The riser of CFB is $2.83 \mathrm{~m}$ high with an internal diameter of $50 \mathrm{~mm}$. The riser is composed of five sections each $460 \mathrm{~mm}$ in height to match the height of the ECT sensor $(400 \mathrm{~mm})$ plus two rubber flanges (30 $\mathrm{mm}$ each). This arrangement enables ECT measurements to be obtained every $460 \mathrm{~mm}$ along the riser. The main air goes into the riser from the bottom through a porous, sintered copper frit. The gas velocity is controlled by a mass flowmeter (Omega FMA 5443 mass flow controller) in the range 0 to $200 \mathrm{~L} \mathrm{~min}^{-1}$, which corresponds to a superficial velocity in the riser of up to 1.70 $\mathrm{m} \mathrm{s}^{-1}$. In these experiments dry air was used. The mixture of air and solids flow out of the riser through an L-type exit and then air and solids are separated in a cyclone. The air flows out of the cyclone through a filter bag. The solids enter into the downcomer with an internal diameter of 30 $\mathrm{mm}$. The solids return from the downcomer to the riser through a U-valve. The air for the Uvalve is regulated by a rotameter and the superficial air velocity in the U-valve is kept constant at 
$0.01 \mathrm{~m} / \mathrm{s}$. The solids flux was measured by closing a butterfly valve in the downcomer and measuring the accumulated height of the particles. The differential pressure was measured by a pressure sensor (Omega PX162-027D5V) through a Labview program. The signal collection frequency for the pressure measurements was about $500 \mathrm{~Hz}$.

The particles for the experiments are silica-alumina catalyst support. The particle density is $1530 \mathrm{~kg} \mathrm{~m}^{-3}$ and the diameter is $63 \mu \mathrm{m}$. The minimum fluidisation velocity is $0.002 \mathrm{~m} / \mathrm{s}$. The experiments were performed with an initial bed height in the riser of $0.255 \mathrm{~m}$ (low inventory) and $0.5 \mathrm{~m}$ (high inventory). When the solids are fully fluidised in the CFB, a dense region of particles remains in the base of the riser to a height of $0.2 \mathrm{~m}$ or $0.37 \mathrm{~m}$ and the other solids are distributed between the cyclone and downcomer. The solids hold up in the riser was estimated by loading the CFB with the specified initial bed height. The CFB was then run until steady state was achieved, at which point the bed was shut down. The quantity of solids remaining in the riser were used as an estimate of the solids hold up in the riser during steady state. Thus, approximately $76 \mathrm{vol} \%$ of the initial solids remains in the riser and $24 \mathrm{vol} \%$ of the initial solids are transported into the downcomer.

\subsection{Electrical capacitance tomography measurements}

An Industrial Tomography Systems m3c ECT system was used to collect the capacitance measurements in the experiments on the circulating fluidised bed. The diameter of the sensor tube is $48.5 \mathrm{~mm}$ and height is $400 \mathrm{~mm}$. There are 12 electrodes arranged uniformly around the insulating tube. Each electrode is $10 \mathrm{~mm}$ wide and $70 \mathrm{~mm}$ long with a $1.5 \mathrm{~mm}$ insulation gap and $1.66 \mathrm{~mm}$ earth between each electrode. A radial and axial guard and earth screen surrounds the electrodes. The instrument measures the capacitance across each electrode pair [46]. In total 66 independent capacitance data are measured for each image. The image is reconstructed as a $32 \times$ 32 grid of square pixels using a linear back projection algorithm. Prior to reconstructing the image, the capacitance data were normalised using

$$
\lambda=\frac{C_{\text {real }}-C_{\text {low }}}{C_{\text {high }}-C_{\text {low }}}
$$


where $C_{\text {real }}$ is the measured capacitance, $C_{\text {low }}$ is the capacitance when the sensor is filled with the low permittivity material (air), and $C_{\text {high }}$ is the capacitance when the sensor is filled with the high permittivity material (a tapped bed of silica-alumina powder).

The principle of ECT is to use the relationship between local permittivity and capacitance to predict the local permittivity. The local permittivity is determined by the combination of gas and solids phases present. Thus, the solids fraction distribution can be obtained through the local permittivity. The image intensity $G$ is related to the permittivity of the high and low calibration measurements by:

$$
G=\frac{\varepsilon_{p m, \text { real }}-\varepsilon_{p m, \text { low }}}{\varepsilon_{p m, h i g h}-\varepsilon_{p m, l o w}}
$$

The solids fraction is related to the permittivity by the Maxwell-Garnett [47] or Bruggeman [48] equations. However, generally a simplified expression is used to estimate the local solids fraction $[49,50]$ :

$$
\varepsilon_{s}=G \times \varepsilon_{s, p a c k}
$$

Since the ECT system exhibits nonlinearity, the linear back projection for image reconstruction can result in overshooting $(>1)$ and undershooting $(<0)$ for normalized permittivity in some regions. The simplest thresholding technique for this is a truncation method where the undershooting $(<0)$ components assume a value of 0 and overshooting $(>1)$ components assume a value of 1 [51]. Pugsley et al. verified electrical capacitance tomography measurements with an optical fibre probe in the fluidised beds [52]. For the circulating fluidised bed, the difference of time-averaged radial profiles measured by two methods is below $10 \%$ with ECT image reconstruction LBP.

\subsection{Two fluid model simulations}

In this work, the computational fluid dynamics package MFIX (Multiphase flow with Interphase eXchanges) is used to simulate the fluidised beds. The governing equations consist of mass and momentum conservation equations with the Kinetic Theory of Granular Flow (KTGF) used for closure of the granular phase properties. Full details of the MFIX equations and solver are 
provided by NETL [53]. Granular flows may transmit stresses through collisions between particles and enduring contacts of particles [54]. To characterize stress transmission associated with enduring contact, the Schaeffer stress model is used when the voidage is below 0.5 . Although widely used for simulation of Geldart group B particles, the traditional Gidaspow drag model [55] is known to be inaccurate when simulating Geldart group A powders. Therefore in addition to the Gidaspow drag model, two drag models are considered here that attempt to describe the drag when sub-grid scale structure is present. Firstly, the revised Gibilaro model was used [6] with $\mathrm{C}=0.25$, which is in the middle of the range recommended for Geldart Group A particles. Secondly, the EMMS [44] drag model was used. Several forms of the EMMS drag equations are available in the literature using slightly different methods and particles [44,56,57]. In theory, the equations should be derived for the specific particles to be used. However, it is common to use the published equations directly as the drag does not change appreciably if the particles are relatively similar $[31,44]$. Here, the EMMS equations Lu et al. derived for particles with $\rho=930 \mathrm{~kg} / \mathrm{m}^{3}$ and $d_{p}=54 \mu \mathrm{m}$ were used. Also note that a filtered drag model was not used here owing to the small geometry of the system. For this geometry and correspondingly fine grid size, the filtered drag model yields a drag model that is similar to a traditional drag model. Equally, in this geometry the bubble-structure based drag model [28] is not appropriate as bubbles are larger than the size of the computational cells used.

The simulations of the dense fluidised bed were performed using an initial packed bed height, $H_{\text {pack }}=120 \mathrm{~mm}$ and superficial gas velocity $U_{g}=0.25,0.35,0.45 \mathrm{~m} / \mathrm{s}$. A three-dimensional (3D) cylindrical mesh of dimensions $10(r) \times 120(z) \times 10(\theta)$ was used, corresponding to a fluidised bed with the diameter of $50 \mathrm{~mm}$ and height of $0.6 \mathrm{~m}$. Gas enters the bed through the base of the column using a constant mass flow. The flow through the outer most cells in the radial direction was reduced relative to the flow through the centre of the bed to account for the $40 \mathrm{~mm}$ diameter of the porous glass frit used in the experiments. Further details of the set up of the simulation are given in Table 2.

The simulations of the riser of the circulating fluidised bed were performed using a 3D cylindrical mesh of dimensions $9 \times 283 \times 12(r \times z \times \theta)$ corresponding to the dimension of the riser $\left(25 \mathrm{~mm}(r) \times 2830 \mathrm{~mm}(z) \times 360^{\circ}(\theta)\right)$, as shown in Figure 3 . The solid inlet is located from $100 \mathrm{~mm}$ to $140 \mathrm{~mm}$ above the gas distributor and covers angles $\theta$ from $30^{\circ}$ to $120^{\circ}$. The solid 
outlet is located $2780 \mathrm{~mm}$ to $2830 \mathrm{~mm}$ above the gas distributor and covers $\theta$ from $0^{\circ}$ to $180^{\circ}$. The simulations were initialised with a dense bed of solids at the base and a dilute freeboard. The voidage in the dense region was set to 0.6 and the height of the dense bed was set to $80 \mathrm{~mm}$ (low inventory) or $340 \mathrm{~mm}$ (high inventory). The voidage in the freeboard was set to 0.97 and the initial gas velocity was $0.04 \mathrm{~m} \mathrm{~s}^{-1}$. The settings for the initial bed height in the riser are designed to approximate the solids hold up in the experimental measurements. In the experiments, it was observed that approximately 24 vol. $\%$ of the particles initially in the bed were transferred across to the cyclone and downcomer when the CFB was operating in the steady state. In addition, the experimental set up contained no particles in the free board region initially. The gas for the CFB enters from the bottom of the riser with constant mass flow. The solids flowing out of exit at the top of the riser are fed back to the inlet at the bottom of the riser without any time delay. Thus, the solids flux is automatically adjusted to achieve a constant solids holdup. Further details of the simulation parameters for the CFB are given in Table 2.

In both systems, the second-order total variation diminishing (TVD) Minmod discretization scheme is applied during the simulations. The numerical residuals for all equations are set to $10^{-3}$. The average time-step is $1 \times 10^{-4} \mathrm{~s}$ with an adaptive time stepping method used. The JohnsonJackson boundary condition was used for the solids at the walls with a specularity coefficient of 0.6. Lower values were tested but these were found to produce unrealistically high downwards velocities at the wall. A value of 0.6 is within the normal range reported in the literature [58-61]. The total simulation duration is 20 seconds for dense fluidised bed and 30 seconds for CFB. Results from the initial simulations were discarded and analysis was performed only on the final 10 seconds of the simulation. Simulations were confirmed to be in steady state by comparing the analysis in two 5 second blocks. Simulations were performed on a desktop PC equipped four processors (Intel $^{(\mathrm{R})} \mathrm{Core}^{(\mathrm{TM})}$ i5-2500 CPU @ 3.30GHz) and 7.7 GB of memory. The length of time required to compute the results for each simulation varied but was typically between 1 and 3 days.

\section{Results and Discussion}

The investigation was performed in three stages. Initially a sensitivity analysis was carried out to determine the effect of various parameters used in the simulations. The objective here was to 
ensure that parameters that were not well defined during the simulations did not adversely affect the simulation results. The second phase of the investigation involved performing simulations of a bubbling fluidised bed for which experimental MRI data were available from the literature. Finally, a CFB was built and ECT and pressure measurements were acquired on this fluidised bed. For comparison simulations of this CFB were also performed. The results of each of these phases of work are described below.

\subsection{Sensitivity analysis}

The initial sensitivity analysis was performed using a base case simulation of a superficial gas velocity of $0.45 \mathrm{~m} \mathrm{~s}^{-1}$ with the revised Gibilaro drag model in the bubbling fluidised bed. The parameters investigated were the mesh, the boundary condition at the central axis, the coefficient of restitution, and the onset of frictional forces in the particle stress model.

Figure 4 shows the time averaged voidage simulated in the fluidised bed for mesh sizes of $5 \times 60$ $\times 5,8 \times 96 \times 8,10 \times 120 \times 10$, and $12 \times 144 \times 12$ in the $r, z$ and $\theta$ directions, respectively. At the coarsest mesh setting, the void is highest close to the wall of the fluidised bed and is at a minimum in the centre of the bed. As the mesh is refined the voidage in the centre of the bed increases slightly, whilst it decreases significantly at the walls. Experimentally, it is expected that the voidage will be greatest in the centre of the bed and lowest at the walls indicating that the coarsest mesh is not sufficiently refined to capture the fluidisation dynamics accurately. The difference in the simulated voidage profile gets progressively less significant as the grid is refined indicating that the $10 \times 120 \times 10$ grid is sufficient for achieving an almost grid independent simulation. It took approximately 18-24 hours to simulate $20 \mathrm{~s}$ of real time fluidisation using the $10 \times 120 \times 10$ grid, whilst approximately 72 hours were required with the $12 \times 144 \times 12$ grid. Therefore, given the small benefit of using the finer resolution grid, all further investigations were performed using the $10 \times 120 \times 10$ grid.

It is well known that simulations using cylindrical coordinate systems can be sensitive to the definition of the boundary condition at the $r=0$ position, i.e. along the central axis of the fluidised bed $[62,63]$. Therefore, the following four boundary conditions were investigated:

Scheme 1: $w_{r(0), \theta}=-w_{r(1), \theta}$ 
Scheme2: $u_{r(0)}=u_{g x, j} \cos \theta_{k}+w_{g z, j} \sin \theta_{k}$

Scheme3: $u_{r(0), \theta}=\frac{\left(u_{r(1), \theta+\pi}-u_{r(1), \theta}\right)}{2}$

Scheme4: $u_{r(0), \theta}=-u_{r(1), \theta}$

where $w$ is the velocity along the $\theta$ direction, $u$ is the velocity along the $r$ direction and $r$ and $\theta$ are the spatial coordinates. The resulting time averaged voidage profiles are shown in Figure 5. The time averaged voidage shows no significant difference between the four boundary conditions tested, with all approaches yielding approximately the same time averaged voidage profile. A closer look at the voidage distribution at individual time points during the simulation was likewise unable to produce any clear difference between these boundary conditions. Similar observations were made of the time averaged solids velocity (results not shown). Therefore, Equation 4 was used for all further investigations.

Finally simulations were performed changing the coefficient of restitution $e$ from 0.80 to 0.99 and the voidage at the onset of the frictional forces $\varepsilon_{\mathrm{gf}}{ }^{*}$ from 0.39 to 0.50 . These represent the maximum realistic variation that is possible for each parameter. The time averaged voidage profiles from these simulations are shown in Figure 6. The resulting profiles were all consistent to within $2 \%$, indicating that neither parameter influences the simulations significantly. Therefore, all subsequent simulations were performed using the standard parameters $e=0.90$ and $\varepsilon_{\mathrm{gf}}^{*}=0.50$.

\subsection{Bubbling fluidised bed}

TFM simulations of the bubbling fluidised bed were performed at superficial gas velocities of

$0.25 \mathrm{~m} \mathrm{~s}^{-1}, 0.35 \mathrm{~m} \mathrm{~s}^{-1}$, and $0.45 \mathrm{~m} \mathrm{~s}^{-1}$. The resulting time averaged voidage profiles are compared with previously published MRI measurements of the voidage obtained from a similar experimental system in Figure 7(a) [19]. The voidage distribution is shown along the horizontal direction at a bed height of $100 \mathrm{~mm}$, which is $20 \mathrm{~mm}$ below the slumped bed height in this system. In the experiment, the MRI time-averaged voidage distribution showed a maximum voidage in the centre of the fluidised bed of $0.73,0.76,0.80$ for $0.25 \mathrm{~m} / \mathrm{s}, 0.35 \mathrm{~m} / \mathrm{s}$ and $0.45 \mathrm{~m} / \mathrm{s}$ 
and a minimum voidage at the walls of $0.55-0.60$. These results suggest that the voidage at the wall is only slightly greater than the voidage at the minimum fluidisation state, which was 0.50 . The experimentally measured voidage distribution is approximately radially symmetric.

Figure 7(b) shows the voidage profiles using the revised Gibilaro drag. The simulated voidage distributions resemble parabolic curves. The maximum voidage is situated in the bed centre and the minimum voidage is located at the wall. The maximum voidage is $0.73,0.76$ or 0.81 and the minimum voidage is around $0.55-0.60$ near the wall when the gas velocity is $0.25 \mathrm{~m} / \mathrm{s}, 0.35 \mathrm{~m} / \mathrm{s}$ or $0.45 \mathrm{~m} / \mathrm{s}$. These results are in good agreement with the experimentally measured voidage distribution. The voidage profiles predicted when using the EMMS drag model in Figure 7(c) show significantly less radial variation. In this case, the voidage in the centre of the pipe is 0.56 , 0.67 , or 0.69 whilst the voidage at the wall is $\sim 0.60$.

In order to quantify the accuracy of the simulated voidage profiles using the two drag models, an error was calculated from:

$$
\delta_{\exp }=\frac{\sqrt{\sum_{i}^{N}\left|\varepsilon_{g i}-\varepsilon_{g i, \exp }\right|^{2}}}{\sqrt{\sum_{i}^{N} \varepsilon_{g i, \exp }^{2}}}
$$

Where $\varepsilon_{\mathrm{gi}}$ is the voidage in the $i$ th cell in the radial direction in the simulation and $\varepsilon_{\text {gi,exp }}$ is the corresponding voidage measured experimentally. At $U_{g}=0.25 \mathrm{~m} / \mathrm{s}, 0.35 \mathrm{~m} / \mathrm{s}$ and $0.45 \mathrm{~m} / \mathrm{s}$, the errors $\left(\delta_{\text {exp }}\right)$ of voidage distribution for revised Gibilaro drag model are $4.6 \%, 4.9 \%$ and $4.9 \%$, and for the EMMS drag model are $11.8 \%, 10.0 \%$ and $11.2 \%$, respectively. These errors vary by less than $1 \%$ when considering profiles along different directions in the simulations, confirming that the flow is approximately radially symmetric.

In addition to the time averaged voidage distribution, MRI measurements of the probability distribution of the solids velocity were available, as shown in Figure 8. The probability density of the solids velocity was obtained in the centre of the bed at a height of $50 \mathrm{~mm}$ above the distributor. These probability distributions were obtained from a series of instantaneous measurements of the local average velocity, thus they are directly comparable to the average velocity data obtained from the TFM simulations. The results show that the most common 
velocities are between $-0.5 \mathrm{~m} \mathrm{~s}^{-1}$ and $1.5 \mathrm{~m} \mathrm{~s}^{-1}$, with the most common velocity increasing slightly with increasing superficial gas velocity. In all cases, the velocity distributions measured in the bed centre show a slight but significant skew.

The probability distribution of the velocity obtained from the TFM simulation using the revised Gibilaro drag is shown in Figure 8(b). The most common velocity in these simulations ranges from $0.2 \mathrm{~m} \mathrm{~s}^{-1}$ to $0.5 \mathrm{~m} \mathrm{~s}^{-1}$. These velocities are slightly higher than was seen experimentally. In addition, the variation in velocities seen is slightly reduced compared with the experiments. For example, at a superficial gas velocity of $0.25 \mathrm{~m} \mathrm{~s}^{-1}$, the experimental velocities were between $0.5 \mathrm{~m} \mathrm{~s}^{-1}$ and $1.5 \mathrm{~m} \mathrm{~s}^{-1}$, whereas the velocities in these simulations were between $-0.4 \mathrm{~m} \mathrm{~s}^{-1}$ and 1 $\mathrm{m} \mathrm{s}^{-1}$. Overall though the velocity distributions obtained from the TFM simulations with the revised Gibilaro drag model are in fair agreement with the experimentally measured results.

The probability distributions obtained from the TFM simulations with the EMMS drag model are shown in Figure 8(c). All of these simulations show that the most common velocity is $<0 \mathrm{~m} \mathrm{~s}^{-1}$, or in other words downwards. This is in sharp contrast to the experimental results. The velocity distributions are highly skewed, with few observations of velocities that were more negative than the most common velocities, but high upwards velocities were relatively common. The skew in these distributions was therefore even more pronounced that that seen experimentally. Overall, the distribution of the solids velocity with the EMMS drag model does not agree well with that observed experimentally.

In summary, the simulations using the revised Gibilaro drag model were found to be in fair agreement with the experimentally measured voidage and velocity distributions in the bubbling fluidised bed. However, the simulations with the EMMS drag model were not found to be very representative, with markedly smaller variations in the voidage across the pipe and significantly more observations of downward moving particles in the centre of the bed than were seen experimentally. This difference is attributed to the EMMS drag model being designed on the basis that each cell contains clusters and a dilute suspension of particles. In a dense fluidised bed such an assumption is unlikely to be valid.

\subsection{Circulating fluidised bed}


Experiments were performed using the CFB with superficial gas velocities of between $0.88 \mathrm{~m} \mathrm{~s}^{-1}$ and $1.70 \mathrm{~m} \mathrm{~s}^{-1}$. The lowest superficial gas velocity considered corresponds to the onset of observable solids circulation, whilst the highest superficial gas velocity was limited by the compressed air supply. Experiments were performed with an initial settled bed height in the riser of $0.255 \mathrm{~m}$ (low inventory) and $0.500 \mathrm{~m}$ (high inventory) in order to change the height at which the transition from a lower voidage to a higher voidage occurs in the riser. In all cases, a coreannular flow is established with particles concentrated in the wall region of the riser, where clear "strand" clusters are seen. For all these gas velocities, there is significant elutriation of particles. Some of these particles settle out along the horizontal pipe connecting the riser exit and the entrance to the cyclone. However, the majority of the particles are recycled through the cyclone and the downcomer. Particles flow freely from the U-valve to the riser, with few particles remaining in the slanted tube connecting the two sections of the process.

The voidage in the riser was measured using both pressure drop and ECT, as shown in Figure 9. The voidage from the pressure drop was calculated by assuming the particle acceleration and wall friction are negligible. Therefore, the solids fraction can be obtained from the pressure measurement using:

$$
\varepsilon_{s}=\frac{\Delta P_{m}}{\rho_{s} g H}
$$

where $\Delta P_{m}$ is the measured pressure drop, $H$ is the height between the two pressure tappings, $\rho_{\mathrm{s}}$ is the density of the solid and $g$ is the acceleration due to gravity; the density of the air is negligible here. For the ECT, the solids fraction $\varepsilon_{\mathrm{s}}$ along the axial direction was estimated from the average solid fraction of the cross section of the bed obtained from:

$$
\varepsilon_{s}=\frac{\sum_{i=1}^{N} G_{i}}{N} \times \varepsilon_{s, \max },
$$

where $G_{\mathrm{i}}$ is the normalised permittivity obtained from the ECT image, $N$ is the number of pixels in the image within the pipe and was equal to 812 for the images obtained here, and $\varepsilon_{\mathrm{s}, \max }$ is the solid fraction in the tapped bed measurement used to normalise the capacitance data. For the low inventory measurements, both the ECT and pressure drop show that the voidage increases from 
$\sim 0.97$ with increasing bed height to a maximum of almost 1 at a bed height of $1.8 \mathrm{~m}$, the voidage decreases again towards the top of the riser to a value of $\sim 0.99$. The increase in solids concentration towards the top of the riser is due to the effect of the solids exit. Similar trends are observed for all gas velocities. For the high inventory measurements, a clear s-shaped axial voidage profile is observed with low voidage for heights below $\sim 1.0 \mathrm{~m}$ and high voidage, similar to that seen in the low inventory case, for heights above $\sim 1.0 \mathrm{~m}$. The height at which the transition from low voidage to high voidage occurs decreases with increasing superficial gas velocity. When the gas velocity is between $0.88 \mathrm{~m} / \mathrm{s}$ and $1.21 \mathrm{~m} / \mathrm{s}$, the transitional height between dense phase and dilute phase is about $1.395 \mathrm{~m}$; for gas velocities between $1.37 \mathrm{~m} / \mathrm{s}$ and $1.70 \mathrm{~m} / \mathrm{s}$, the transitional height is $0.975 \mathrm{~m}$. It is likely that the change in height of the transition point varies smoothly with increasing gas velocity, however measurements were only possible every $0.46 \mathrm{~m}$ owing to the length of the ECT sensor used. Similar trends are observed in both the ECT and pressure measurements of the column.

A quantitative comparison of the ECT and pressure measurements indicates that the pressure measurements consistently show a slightly higher voidage than the ECT measurements. The lower voidage in the ECT measurements likely arises from uncertainty in the solids fraction during the tapped bed calibration experiment or errors in the simple linear back project reconstruction algorithm used here. This slight error in voidage should be considered when analysing the radial distribution of the voidage obtained from the ECT. It should also be noted that the voidage obtained from the pressure drop measurements is an approximation only. The pressure drop will be influenced by acceleration of the gas and solid, as well as wall friction, neither of which was considered here. In all cases this would likely lead to an underestimate of the voidage. That the ECT measurements show a consistently lower voidage than the pressure measurements indicates that any errors associated with the acceleration or wall friction are small. The voidage obtained from the ECT is shown in Figure 10 across the diameter of the riser at bed heights of $0.475 \mathrm{~m}, 1.395 \mathrm{~m}$ and $2.315 \mathrm{~m}$. The typical core-annulus structure is clearly identified with high solids fraction in the wall zone and low solids fraction in the bed centre. The voidage distribution is not completely symmetrical with a slightly higher solids concentration on the left side than on the right side. For example, at a bed height of $1.395 \mathrm{~m}$ and $1.70 \mathrm{~m} \mathrm{~s}^{-1}$, the voidage close to the wall on the left side is 0.945 (low inventory) or 0.934 (high inventory), whilst on the right side it is 0.955 (low inventory) or 0.942 (high inventory). The difference in voidage arises 17 
because the solids feed from the U-valve and the exit solids are both on the same side of the riser, and the solids concentration is higher on the side of the solids feed and exit. At gas velocities greater than $1.37 \mathrm{~m} \mathrm{~s}^{-1}$, the diameter of the high voidage core is largely independent of gas velocity and decreases from about $37.5 \mathrm{~mm}, 28.1 \mathrm{~mm}$ to $25.0 \mathrm{~mm}$ in the high inventory case. At gas velocities below $1.37 \mathrm{~m} \mathrm{~s}^{-1}$, the core-annulus structure begins to break down higher in the column. When the gas velocity is less than $1.21 \mathrm{~m} \mathrm{~s}^{-1}$, the voidage distribution at the top of the column approaches 1 for the entire cross-section of the column. For the high inventory experiments, at a height of $0.475 \mathrm{~m}$, the voidage near the wall increases with increasing gas velocity. At heights of $1.395 \mathrm{~m}$ and $2.315 \mathrm{~m}$, the voidage decreases with increasing superficial gas velocity. The ECT measurements show that the voidage in the centre of the bed is close to 1 . It is likely that the measured voidage here is slightly greater than the true voidage owing to saturation of the ECT signal and error in the LBP reconstruction algorithm used. However, previous measurements by MRI, ECT and optical fibre probes have obtained a voidage of between 0.98 and 1 in the core of a riser [19,39] under similar operating conditions, indicating that any error in the centre of the riser is small.

Simulations were performed for the riser of the CFB for superficial gas velocities of between $0.88 \mathrm{~m} \mathrm{~s}^{-1}$ and $1.70 \mathrm{~m} \mathrm{~s}^{-1}$ and for the low inventory and high inventory cases. The average voidage at a given height was calculated from:

$$
\bar{\varepsilon}_{g, \text { axial }}=\frac{\sum_{i=1}^{N} \varepsilon_{g, i} \cdot S_{i}}{\sum_{i=1}^{N} S_{i}}
$$

Where $N$ is the number of cells in the cross section of the riser, in this case 108, $S_{i}$ is the area of the $i$ th cell in the cross section and $\varepsilon_{g, i}$ is the voidage in the $i$ th cell. The axial voidage distribution obtained when using the Gidaspow drag model is shown in Figure 11(a). The simulated voidage was approximately 0.96 and is almost independent of height and superficial gas velocity. The simulated voidage is therefore in poor agreement with the experimentally measured voidage, as has been shown previously in simulations using conventional drag models and group A powders [12]. The axial voidage distribution estimated by TFM simulation with the 
revised Gibilaro drag is shown in Figure 11(b). These simulations show that the voidage is a strong function of height and superficial gas velocity. For example, when the gas velocity increases from $0.88 \mathrm{~m} \mathrm{~s}^{-1}$ to $1.70 \mathrm{~m} \mathrm{~s}^{-1}$, the voidage at the bed bottom increases from 0.90 to 0.93 and the voidage at the bed top decreases from $\sim 1$ to 0.99 . Thus these simulations are closer to the experimental result. However, the voidage at the bottom of the bed is much lower than the experimentally measured voidage of about 0.97, as shown in Figure 9(a) and (c). The axial voidage profiles predicted by TFM simulation with the EMMS are shown in Figure 11(c). These results indicate that the voidage is quite a strong function of superficial gas velocity, but is almost constant along the height of the riser. This behaviour is in-line with the experimental measurements shown in Figure 9(a) and (c). In order to test the effectiveness of the EMMS drag model further, the CFB was also simulated for the high inventory case. The predicted axial voidage distributions are shown in Figure 11(d). These simulations show the characteristic sshaped voidage profile with a low voidage in the base of the riser and a high voidage at the top of the riser. The transitional bed height for the voidage distribution curve is about $0.975 \mathrm{~m}$. Below this height, the voidage is $0.80-0.87$, whilst above this height the voidage is greater than 0.93 for all heights. The height at which the transition from low voidage to high voidage occurs is somewhat below that measured experimentally. It is likely that this discrepancy arises from the fact that only the riser was simulated and not the entire CFB. Further, the simulations return solids exiting the top of the riser to the base of the riser without any time delay. Both of these factors may influence the solids hold up in the simulations, especially in the entrance region of the riser. However, the key point from these simulations is in identifying whether the different drag models predict a transition between low and high voidage, not the specific location of this transition. These results are again in-line with the experimental results which show that the voidage at the bottom of the riser is $0.85-0.94$ and the voidage at the top of the riser is 0.96 0.99, as shown in Figure 9(b) and (d).

The voidage distribution across the diameter of the pipe obtained from the simulations is shown in Figure 12 for the revised Gibilaro and EMMS drag mdoels. For both drag models, the simulations generally show a lower voidage at the wall and higher voidage in the centre of the riser, which is consistent with the experimentally measured voidage distribution. High in the riser the simulations with the revised Gibilaro model show a significantly higher voidage than the simulations with the EMMS model, whilst the opposite trend is seen at a height of $0.475 \mathrm{~m}$. 
The experimental measurements show a voidage that is closer to the voidage obtained when using the EMMS drag model, especially at a height of $0.475 \mathrm{~m}$ where the revised Gibilaro model predicts the voidage to be between 0.85 and 0.95 , but the experimental and EMMS models both show that the voidage exceeds 0.9 throughout the riser. Thus, the profiles obtained from the simulations with the EMMS model are closer to the experimentally measured profiles than the profiles obtained with the revised Gibilaro model, consistent with the axial voidage profiles shown in Figure 11. However, there are some significant differences between the radial voidage distributions in the simulations and the experiments. The voidage at the wall in the simulations is consistently higher than that measured experimentally, whilst the voidage in the centre of the riser is consistently lower. This difference is seen most clearly in the simulations at a superficial gas velocity of $1.70 \mathrm{~m} \mathrm{~s}^{-1}$ where the voidage in the centre of the riser is seen to drop to 0.94 , whilst the experiments measure a voidage of $\sim 1$. It was noted earlier that the experimental measurements likely over-estimated the voidage in the centre of the bed, however it is unlikely that the error in the experimental measurements was sufficient to explain the discrepancy seen here. Thus, although the EMMS model is effective at describing the axial voidage profile, it does not seem to fully capture the fluidisation dynamics in the riser.

To further explore the accuracy of the CFD simulations, experiments were performed to measure the solids flux and these were compared with the solids flux obtained from the simulations, as shown in Figure 13. The experimental solids flux was obtained by closing a porous butterfly valve in the downcomer and measuring the time taken to accumulate a height of either $50 \mathrm{~mm}$ or $100 \mathrm{~mm}$ of particles above the valve. It is worth noting that a small portion of the solids slipped around the outside of the butterfly valve, thus the experimentally measured solids flux likely underestimates the true solids flux. However, the bias introduced by this solids slip was estimated to correspond to $<10 \%$ of the measured solids flux. For the simulations, the solids flux $G_{\mathrm{s}}$ was obtained from the new solids flow across the cross section of bed just below the riser exit,

$$
G_{s}=\frac{\sum_{i=1}^{N} \rho_{s} u_{s} \varepsilon_{s} \cdot S_{i}}{\sum_{i=1}^{N} S_{i}}
$$


where $\rho_{\mathrm{s}}$ is the density of the solids, $u_{\mathrm{s}}$ is the velocity of the solids phase, $\varepsilon_{\mathrm{s}}$ is the solids volume fraction, $S$ is the area of a single pixel in the image, and $N$ is the number of pixels, which in this case was 108. The simulations were performed using the revised Gibilaro, and EMMS drag models, for comparison, a simulation was also performed using the Gidaspow drag model. For both low and high inventories, the solid flux increases with increasing gas velocity in both the experiments and simulations. The experimental measurements indicate that the solids flux increases from $\sim 2 \mathrm{~kg} \mathrm{~m}^{-2} \mathrm{~s}^{-1}$ at a superficial gas velocity of $0.88 \mathrm{~m} \mathrm{~s}^{-1}$, to $\sim 20 \mathrm{~kg} \mathrm{~m}^{-2} \mathrm{~s}^{-1}$ at $1.70 \mathrm{~m} \mathrm{~s}^{-1}$. As expected, the Gidaspow drag model significantly over estimates the measured solids flux, predicting a solids flux in excess of $20 \mathrm{~kg} \mathrm{~m}^{-2} \mathrm{~s}^{-1}$ even at the lowest superficial gas velocity. By contrast, the revised Gibilaro model significantly under predicts the solids flux, predicting a maximum solids flux of $5 \mathrm{~kg} \mathrm{~m}^{-2} \mathrm{~s}^{-1}$ at the highest superficial gas velocity. Only the TFM simulations using the EMMS model estimate the solid flux to be close to that measured experimentally. For example, at $1.70 \mathrm{~m} / \mathrm{s}, G_{s}$ predicted by the EMMS is $28 \mathrm{~kg} \mathrm{~m}^{-2} \mathrm{~s}^{-1}$, compared with $18 \mathrm{~kg} / \mathrm{m}^{2} \mathrm{~s}$ measured experimentally. Although the EMMS model still overestimates the solid flux, the qualitative trend of the change in solid flux with superficial gas velocity is in good agreement with that measured experimentally. The solid flux was not seen to be a strong function of the total solid inventory in either the experiments or the simulations with the EMMS drag model.

Overall, the simulations show that of the drag models considered, the EMMS model is the most effective at characterizing the gas-solid flow in the riser. Simulations with the EMMS model were found to produce good agreement with the axial voidage profile, and fair agreement with the radial voidage profile and solids flux. The revised Gibilaro model assumes all particles form small clusters, but it does not assume that these individual clusters combine to produce the large streamers found in a CFB. On the other hand, the EMMS model is derived on the assumption that particles divide into relatively large clusters and a dilute gas flow of essentially isolated particles. This arrangement of particles is expected to occur within the riser of a CFB. Therefore, it is expected that the EMMS model will describe the gas-solid interaction in the riser more accurately than the revised Gibilaro model.

\section{Conclusions}


Electrical capacitance tomography and magnetic resonance imaging were used to investigate the revised Gibilaro model and the Energy Minimisation Multiscale model for the simulation of Geldart group A powders with the two fluid model. Experiments were performed using cylindrical fluidised beds $50 \mathrm{~mm}$ in diameter with a silica-alumina catalyst support particle of diameter $63 \mu \mathrm{m}$. A dense phase, bubbling fluidised bed and a dilute phase, circulating fluidised bed were studied. The experimental measurements reported here demonstrate that the revised Gibilaro model can be used to predict the voidage and particle velocity distribution in the dense fluidised bed with a high degree of accuracy, however when used to simulate the circulating fluidised bed it underestimates the solids circulation rate by approximately a factor of 4 . The Energy Minimisation Multiscale drag model is able to predict the solids circulation rate in the circulating fluidised bed to within about 50\%, however it does not predict the correct voidage distribution in the dense fluidised bed. The difference in behavior of the two models in the different fluidisation regimes is attributed to the assumptions inherent to each model. The revised Gibilaro model assumes all particles group together in small, essentially isolated, clusters. In contrast, the EMMS model assumes that within each fluid cell there are regions containing relatively large clusters and regions containing only dilute concentrations of particles. It is unlikely that large clusters form in dense fluidised beds, whilst it is known that such clusters are found in the riser of CFBs. Therefore, the findings of these simulations are consistent with the derivations of the drag models. However, this also highlights a limitation of the drag models in that neither is applicable over the entire range of fluidisation conditions. The fact that neither model accurately simulates the entire range of fluidisation conditions raises the question, which drag model should be used when simulating an entire CFB? The results presented here indicate that the riser should be simulated using the EMMS model, however the U-valve and perhaps the base of the riser may be more accurately described using a model such as the revised Gibilaro model. Such an approach is not satisfactory and suggests further work is needed to develop a drag model for the entire range of fluidisation conditions. Initial progress in this has been made in this area [64], however further investigation is required. 


\section{Acknowledgement}

The authors would like to acknowledge the National Energy Technology Laboratory (NETL) of the USA for providing the MFIX two fluid model used in this work. Financial support was provided by the Engineering and Physical Science Research Council (EPSRC) under grant $\mathrm{EP} / \mathrm{K} 008218 / 1$.

\section{References:}

[1] D. Gidaspow, Multiphase flow and fluidisation - continuum and kinetic theory descriptions, Academic Press, 1994.

[2] Y. Tsuji, T. Kawaguchi, T. Tanaka, Discrete particle simulation of two-dimensional fluidized bed, Powder Technol. 77 (1993) 79-87.

[3] T.W. Asegehegn, M. Schreiber, H.J. Krautz, Numerical simulation and experimental validation of bubble behavior in 2D gas-solid fluidized beds with immersed horizontal tubes, Chem. Eng. Sci. 66 (2011) 5410-5427. doi:10.1016/j.ces.2011.07.056.

[4] N. Herzog, M. Schreiber, C. Egbers, H.J. Krautz, A comparative study of different CFDcodes for numerical simulation of gas-solid fluidized bed hydrodynamics, Comput. Chem. Eng. 39 (2012) 41-46. doi:10.1016/j.compchemeng.2011.12.002.

[5] A. Busciglio, G. Vella, G. Micale, L. Rizzuti, Analysis of the bubbling behaviour of 2D gas solid fluidized beds, Chem. Eng. J. 148 (2009) 145-163. doi:10.1016/j.cej.2008.11.010.

[6] T. McKeen, T. Pugsley, Simulation and experimental validation of a freely bubbling bed of FCC catalyst, Powder Technol. 129 (2003) 139-152. doi:10.1016/S00325910(02)00294-2.

[7] S.J. Gelderbloom, D. Gidaspow, R.W. Lyczkowski, CFD Simulations of Bubbling / Collapsing Fluidized Beds for Three Geldart Groups, AIChE J. 49 (2003) 844-858. doi:10.1002/aic.690490405.

[8] S. Zimmermann, F. Taghipour, CFD Modeling of the Hydrodynamics and Reaction Kinetics of FCC Fluidized-Bed Reactors, Ind. Eng. Chem. Res. 44 (2005) 9818-9827. doi:10.1021/ie050490+.

[9] J. Kim, G.Y. Han, Simulation of bubbling fluidized bed of fine particles using CFD, Korean J. Chem. Eng. 24 (2007) 445-450. doi:10.1007/s11814-007-0077-8.

[10] Y. Igci, A.T. Andrews IV, S. Sundaresan, S. Pannala, T. O’Brien, Filtered Two-Fluid 
Models for Fluidized Gas-Particle Suspensions, AIChE J. 54 (2008) 1431-1448. doi:10.1002/aic.11481.

[11] J. Wang, M.A. van der Hoef, J.A.M. Kuipers, Why the two-fluid model fails to predict the bed expansion characteristics of Geldart A particles in gas-fluidized beds: A tentative answer, Chem. Eng. Sci. 64 (2009) 622-625. doi:10.1016/j.ces.2008.09.028.

[12] J. Gao, X. Lan, Y. Fan, J. Chang, G. Wang, C. Lu, et al., CFD Modeling and Validation of the Turbulent Fluidized Bed of FCC Particles, AIChE J. 55 (2009) 1680-1694. doi:10.1002/aic.11824.

[13] S.H. Hosseini, R. Rahimi, M. Zivdar, A. Samimi, CFD simulation of gas-solid bubbling fluidized bed containing FCC particles, Korean J. Chem. Eng. 26 (2009) 1405-1413. doi:10.1007/s11814-009-0220-9.

[14] J. Wang, Y. Liu, EMMS-based Eulerian simulation on the hydrodynamics of a bubbling fluidized bed with FCC particles, Powder Technol. 197 (2010) 241-246. doi:10.1016/j.powtec.2009.09.022.

[15] J.P.K. Seville, C.D. Willett, P.C. Knight, Interparticle forces in fluidisation: a review, Powder Technol. 113 (2000) 261-268. doi:10.1016/S0032-5910(00)00309-0.

[16] E. Helland, H. Bournot, R. Occelli, L. Tadrist, Drag reduction and cluster formation in a circulating fluidised bed, Chem. Eng. Sci. 62 (2007) 148-158. doi:10.1016/j.ces.2006.08.012.

[17] N. Mostoufi, J. Chaouki, Flow structure of the solids in gas-solid fluidized beds, Chem. Eng. Sci. 59 (2004) 4217-4227. doi:10.1016/j.ces.2004.06.006.

[18] H. Li, Q. Zhu, H. Liu, Y. Zhou, The cluster size distribution and motion behavior in a fast fluidized bed, Powder Technol. 84 (1995) 241-246. doi:10.1016/0032-5910(95)02985-B.

[19] D.J. Holland, C.R. Müller, J.S. Dennis, L.F. Gladden, J.F. Davidson, Magnetic Resonance Studies of Fluidization Regimes, Ind. Eng. Chem. Res. 49 (2010) 5891-5899. doi:10.1021/ie901450q.

[20] P. Lettieri, D. Newton, J.G. Yates, Homogeneous bed expansion of FCC catalysts, influence of temperature on the parameters of the Richardson-Zaki equation, Powder Technol. 123 (2002) 221-231. doi:10.1016/S0032-5910(01)00463-6.

[21] J. Wang, M.A. van der Hoef, J.A.M. Kuipers, The role of scale resolution versus interparticle cohesive forces in two-fluid modeling of bubbling fluidization of Geldart A particles, Chem. Eng. Sci. 66 (2011) 4229-4240. doi:10.1016/j.ces.2011.06.004.

[22] S. Benyahia, Fine-Grid Simulations of Gas-Solids Flow in a Circulating Fluidized Bed, AIChE J. 58 (2012) 3589-3592. doi:10.1002/aic.13826.

[23] L.G. Gibilaro, R. Di Felice, S.P. Waldram, P.U. Foscolo, Generalized friction factor and drag coefficient correlations for fluid-particle interactions, Chem. Eng. Sci. 40 (1985) 1817-1823. doi:10.1016/0009-2509(85)80116-0.

[24] P. Li, X. Lan, C. Xu, G. Wang, C. Lu, J. Gao, Drag models for simulating gas-solid flow in the turbulent fluidization of FCC particles, Particuology. 7 (2009) 269-277. 
doi:10.1016/j.partic.2009.03.010.

[25] J. Li, C. Cheng, Z. Zhang, J. Yuan, A. Nemet, F.N. Fett, The EMMS model - its application, development and updated concepts, Chem. Eng. Sci. 54 (1999) 5409-5425. doi:10.1016/S0009-2509(99)00274-2.

[26] J. Wang, W. Ge, J. Li, Eulerian simulation of heterogeneous gas-solid flows in CFB risers: EMMS-based sub-grid scale model with a revised cluster description, Chem. Eng. Sci. 63 (2008) 1553-1571. doi:10.1016/j.ces.2007.11.023.

[27] W. Shuai, Z. Guangbo, L. Guodong, L. Huilin, Z. Feixiang, Z. Tianyu, Hydrodynamics of gas-solid risers using cluster structure-dependent drag model, Powder Technol. 254 (2014) 214-227. doi:10.1016/j.powtec.2013.12.036.

[28] S. Wang, J. Chen, Q. Wang, G. Liu, H. Lu, L. Sun, Evaluation of a bubble-structure dependent drag model for the simulation of bubbling fluidization with Geldart A particles, Powder Technol. 289 (2016) 44-51. doi:10.1016/j.powtec.2015.11.024.

[29] S. Vashisth, A.H. Ahmadi Motlagh, S. Tebianian, M. Salcudean, J.R. Grace, Comparison of numerical approaches to model FCC particles in gas-solid bubbling fluidized bed, Chem. Eng. Sci. 134 (2015) 269-286. doi:10.1016/j.ces.2015.05.001.

[30] C. Loha, H. Chattopadhyay, P.K. Chatterjee, Assessment of drag models in simulating bubbling fluidized bed hydrodynamics, Chem. Eng. Sci. 75 (2012) 400-407. doi:10.1016/j.ces.2012.03.044.

[31] S. Schneiderbauer, S. Puttinger, S. Pirker, Comparative analysis of subgrid drag modifications for dense gas-particle flows in bubbling fluidized beds, AIChE J. 59 (2013) 4077-4099. doi:10.1002/aic.14155.

[32] W.-X. Huang, A. Yan, J. Zhu, Hydrodynamics and Flow Development in a $15.1 \mathrm{~m}$ Circulating Fluidized Bed Riser, Chem. Eng. Technol. 30 (2007) 460-466. doi:10.1002/ceat.200600400.

[33] P. Jiang, H. Bi, S.-C. Liang, L.-S. Fan, Hydrodynamic behavior of circulating fluidized bed with polymeric particles, AIChE J. 40 (1994) 193-206. doi:10.1002/aic.690400202.

[34] M. Louge, H. Chang, Pressure and voidage gradients in vertical gas-solid risers, Powder Technol. 60 (1990) 197-201. doi:10.1016/0032-5910(90)80144-N.

[35] J. Werther, Measurement techniques in fluidized beds, Powder Technol. 102 (1999) 15-36. doi:10.1016/S0032-5910(98)00202-2.

[36] R.F. Mudde, Time-resolved X-ray tomography of a fluidized bed, Powder Technol. 199 (2010) 55-59. doi:10.1016/j.powtec.2009.04.021.

[37] M. Bieberle, F. Barthel, U. Hampel, Ultrafast X-ray computed tomography for the analysis of gas-solid fluidized beds, Chem. Eng. J. 189-190 (2012) 356-363. doi:10.1016/j.cej.2012.02.028.

[38] J. Chaouki, F. Larachi, M.P. Dudukovic, Noninvasive tomographic and velocimetric monitoring of multiphase flows, Ind. Eng. Chem. Res. 36 (1997) 4476-4503. doi:10.1021/ie970210t. 
[39] B. Du, W. Warsito, L.-S. Fan, ECT studies of the choking phenomenon in a gas-solid circulating fluidized bed, AIChE J. 50 (2004) 1386-1406. doi:10.1002/aic.10168.

[40] V. Rimpiläinen, L.M. Heikkinen, M. Vauhkonen, Moisture distribution and hydrodynamics of wet granules during fluidized-bed drying characterized with volumetric electrical capacitance tomography, Chem. Eng. Sci. 75 (2012) 220-234. doi:10.1016/j.ces.2012.03.028.

[41] S. Harms, S. Stapf, B. Blümich, Application of k- and q-space encoding NMR techniques on granular media in a 3D model fluidized bed reactor, J. Magn. Reson. 178 (2006) 30817. doi:10.1016/j.jmr.2005.10.009.

[42] C.R. Müller, D.J. Holland, A.J. Sederman, M.D. Mantle, L.F. Gladden, J.F. Davidson, Magnetic Resonance Imaging of fluidized beds, Powder Technol. 183 (2008) 53-62. doi:10.1016/j.powtec.2007.11.029.

[43] Y.T. Makkawi, P.C. Wright, Electrical capacitance tomography for conventional fluidized bed measurements - remarks on the measuring technique, Powder Technol. 148 (2004) 142 - 157. doi:10.1016/j.powtec.2004.09.006.

[44] B. Lu, W. Wang, J. Li, Eulerian simulation of gas-solid flows with particles of Geldart groups A, B and D using EMMS-based meso-scale model, Chem. Eng. Sci. 66 (2011) 4624-4635. doi:10.1016/j.ces.2011.06.026.

[45] D.J. Holland, Q. Marashdeh, C.R. Müller, F. Wang, J.S. Dennis, L.-S. Fan, et al., Comparison of ECVT and MR Measurements of Voidage in a Gas-Fluidized Bed, Ind. Eng. Chem. Res. 48 (2009) 172-181. doi:10.1021/ie8002073.

[46] C.G. Xie, S.M. Huang, B.S. Hoyle, R. Thorn, C. Lenn, D. Snowden, et al., Electrical capacitance tomography for flow imaging: system model for development of image reconstruction algorithms and design of primary sensors, IEE Proceedings-G. 139 (1992) 89-98.

[47] R. Ruppin, Evaluation of extended Maxwell-Garnett theories, Opt. Commun. 182 (2000) 273-279. doi:10.1016/S0030-4018(00)00825-7.

[48] D.A.G. Bruggeman, Berechnung verschiedener physikalischer konstanten von heterogenen substanzen, I. Dielektrizitähigkeiten der mischkörper aus isotropen substanzen, Ann. Phys. 416 (1935) 636-664.

[49] T. Zhao, M. Takei, K. Masaki, R. Ogiso, K. Nakao, A. Uchiura, Sensor design and image accuracy for application of capacitance $\mathrm{CT}$ to the petroleum refinery process, Flow Meas. Instrum. 18 (2007) 268-276. doi:10.1016/j.flowmeasinst.2007.06.007.

[50] S.M. Rao, K. Zhu, C.-H. Wang, S. Sundaresan, Electrical Capacitance Tomography Measurements on the Pneumatic Conveying of Solids, Ind. Eng. Chem. Res. 40 (2001) 4216-4226. doi:10.1021/ie0100028.

[51] A. Srivastava, K. Agrawal, S. Sundaresan, S.B. Reddy Karri, T.M. Knowlton, Dynamics of gas-particle flow in circulating fluidized beds, Powder Technol. 100 (1998) 173-182. doi:10.1016/S0032-5910(98)00138-7.

[52] T. Pugsley, H. Tanfara, S. Malcus, H. Cui, J. Chaouki, C. Winters, Verification of 
fluidized bed electrical capacitance tomography measurements with a fibre optic probe, Chem. Eng. Sci. 58 (2003) 3923-3934. doi:10.1016/S0009-2509(03)00288-4.

[53] NETL, MFIX, (2015). https://mfix.netl.doe.gov/.

[54] C.S. Campbell, Granular material flows-an overview, Powder Technol. 162 (2006) 208229. doi:10.1016/j.powtec.2005.12.008.

[55] J. Ding, D. Gidaspow, A bubbling fluidization model using kinetic theory of granular flow, AIChE J. 36 (1990) 523-538.

[56] W. Wang, J. Li, Simulation of gas-solid two-phase flow by a multi-scale CFD approachExtension of the EMMS model to the sub-grid level, Chem. Eng. Sci. 62 (2007) 208 - 231.

[57] N. Yang, W. Wang, W. Ge, J. Li, CFD simulation of concurrent-up gas-solid flow in circulating fluidized beds with structure-dependent drag coefficient, Chem. Eng. J. 96 (2003) 71-80.

[58] Y. Igci, S. Sundaresan, Verification of Filtered Two-Fluid Models for Gas-Particle Flows in Risers, AIChE J. 57 (2011) 2691-2707. doi:10.1002/aic.

[59] K. Hong, S. Chen, W. Wang, J. Li, Fine-grid two-fluid modeling of fluidization of Geldart A particles, Powder Technol. (2015). doi:10.1016/j.powtec.2015.07.003.

[60] C. Loha, H. Chattopadhyay, P.K. Chatterjee, Effect of coefficient of restitution in EulerEuler CFD simulation of fluidized-bed hydrodynamics, Particuology. 15 (2014) 170-177. doi:10.1016/j.partic.2013.07.001.

[61] P.C. Sande, S. Ray, Mesh size effect on CFD simulation of gas-fluidized Geldart A particles, Powder Technol. 264 (2014) 43-53. doi:10.1016/j.powtec.2014.05.019.

[62] A. Bakshi, C. Altantzis, A.F. Ghoniem, Towards Accurate Three-Dimensional Simulation of Dense Multi-Phase Flows Using Cylindrical Coordinates, Powder Technol. 264 (2014) 242-255. doi:10.1016/j.powtec.2014.04.052.

[63] V. Verma, N.G. Deen, J.T. Padding, J.A.M. Kuipers, Two-fluid modeling of threedimensional cylindrical gas-solid fluidized beds using the kinetic theory of granular flow, Chem. Eng. Sci. 102 (2013) 227-245. doi:10.1016/j.ces.2013.08.002.

[64] A.H. Ahmadi Motlagh, J.R. Grace, M. Salcudean, C.M. Hrenya, New structure-based model for Eulerian simulation of hydrodynamics in gas-solid fluidized beds of Geldart Group “A” particles, Chem. Eng. Sci. 120 (2014) 22-36. doi:10.1016/j.ces.2014.08.042. 


\section{Figures:}

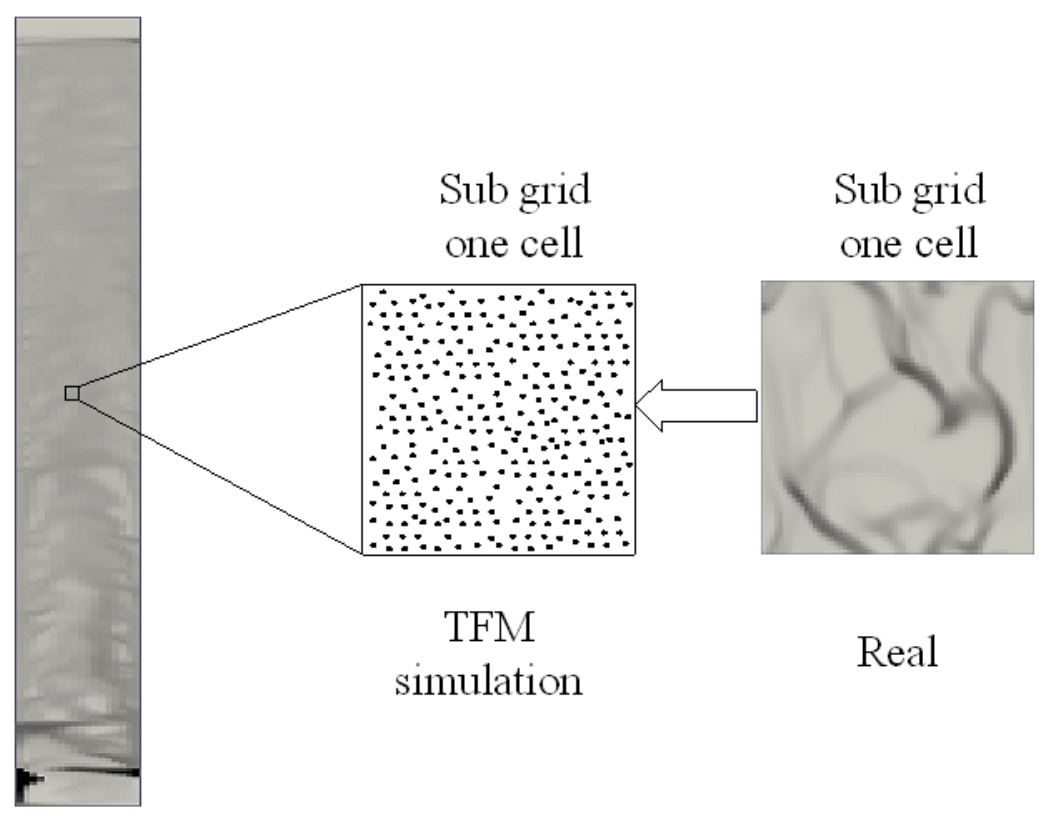

Figure 1. Schematic illustration of the assumption of solids flow in one cell of a TFM simulation and real solids flow in one cell. In the simulation the voidage is assumed to be uniformly distributed, whilst in reality particles may cluster at a length scale that is smaller than the length scale of a single cell. 
a)

Dense fluidised bed

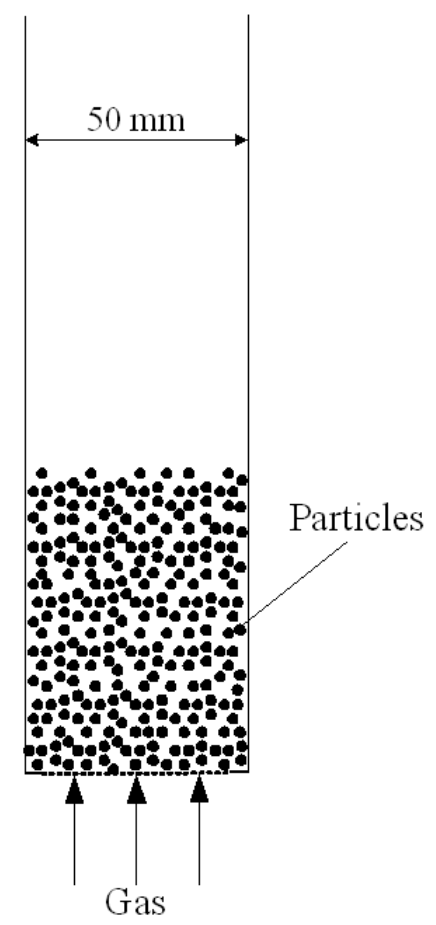

b) Circulating fluidised bed Gas

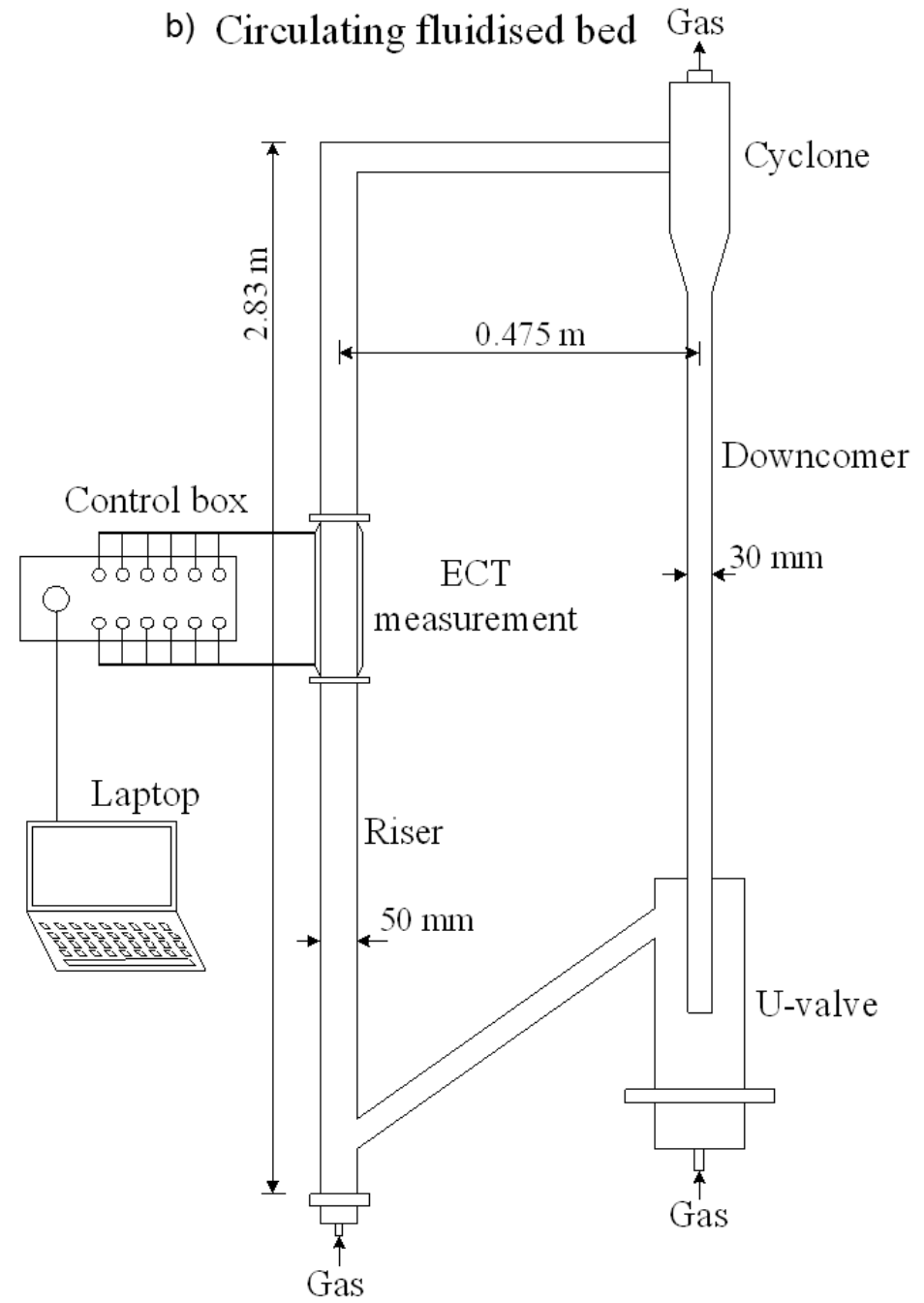

Figure 2 Schematic diagrams of (a) the dense fluidised bed and (b) the circulating fluidised bed used in this work. The gas used in both cases was compressed air at room temperature and 2 bar gauge. 
(a)

(b)
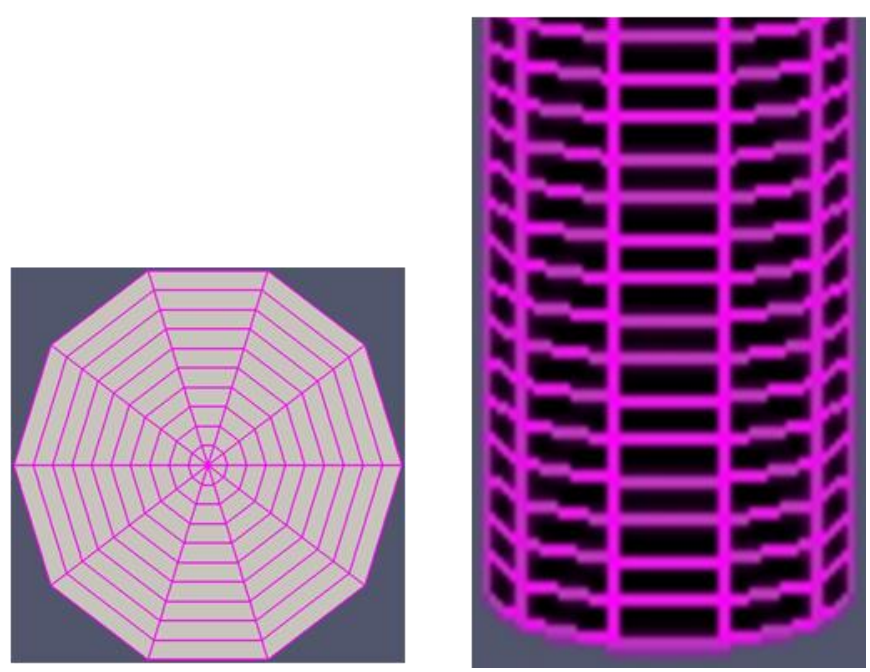

Figure 3 Illustration of the computational grid used in the simulations. Note that although the cells are shown in this figure as being trapezoidal, the simulations were performed in radial coordinates and therefore the cross section of the actual cell geometry describes a circle accurately. (a) shows a cross section through the geometry, (b) shows a perspective view of the the first 15 cells in the vertical direction. 


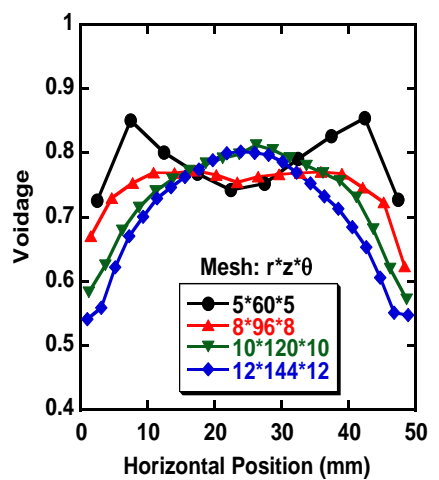

Figure 4 Effect of mesh size on voidage distribution in the fluidised bed for a superficial gas velocity of $0.45 \mathrm{~m} \mathrm{~s}^{-1}$ and the revised Gibilaro drag model. 


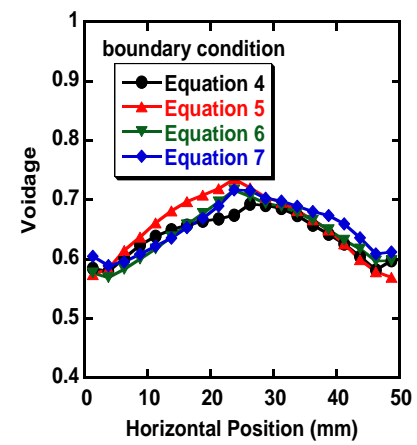

Figure 5 Effect of the definition of the boundary condition on the $r(0)$-axis. Time averaged voidage is shown for a superficial gas velocity of $0.45 \mathrm{~m} \mathrm{~s}^{-1}$ and simulations performed using the revised Gibilaro drag model. The boundary condition was found to have a similarly small impact on the voidage distribution when using the EMMS drag model. 

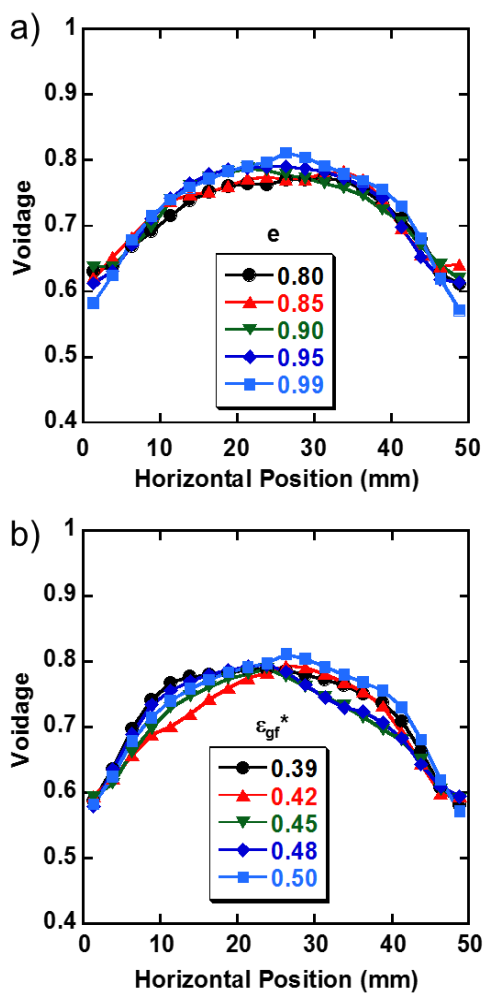

Figure 6 Sensitivity analysis illustrating the effect of (a) the coefficient of restitution and (b) the onset of frictional forces on the voidage distribution. Simulations were performed at a superficial gas velocity of $0.45 \mathrm{~m} \mathrm{~s}^{-1}$ and with the revised Gibilaro drag model. Similar results were found with the EMMS drag model. 

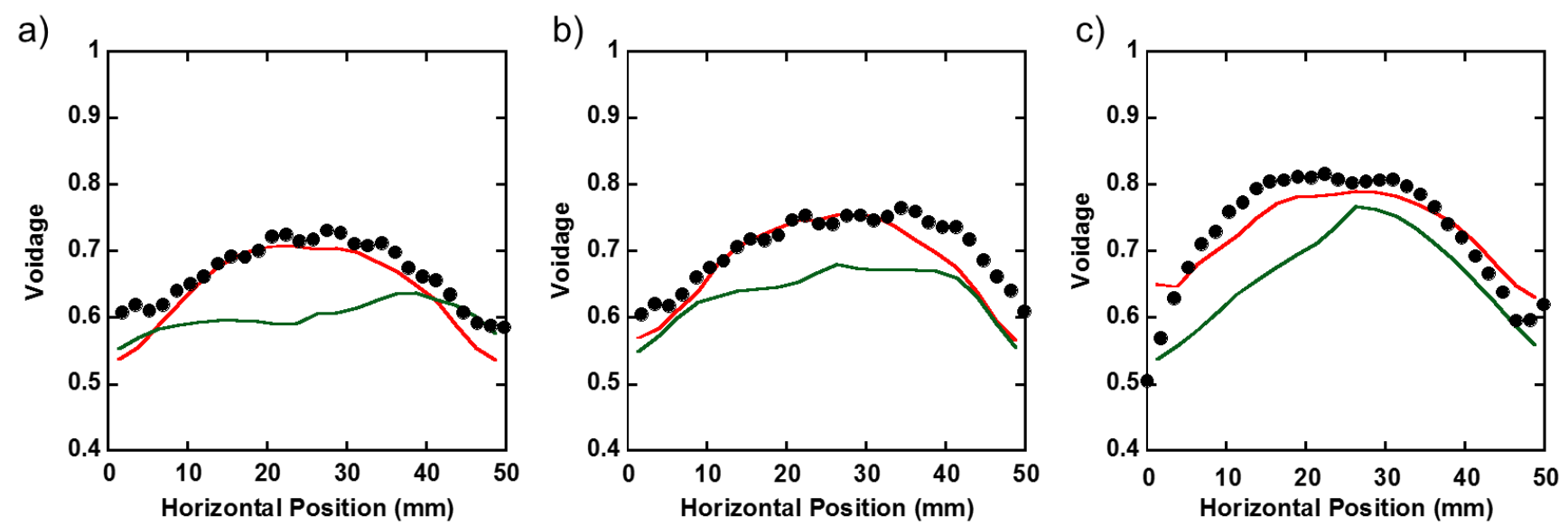

Figure 7 Comparison of voidage distributions obtained from experiments and simulations at a height of $100 \mathrm{~mm}$ above the distributor for a fluidised bed with a settled bed height of $120 \mathrm{~mm}$. The superficial gas velocities considered were (a) $U_{\mathrm{g}}=0.25 \mathrm{~m} \mathrm{~s}^{-1}$, (b) $U_{\mathrm{g}}=0.35 \mathrm{~m} \mathrm{~s}^{-1}$, and (c) $U_{\mathrm{g}}$ $=0.45 \mathrm{~m} \mathrm{~s}^{-1}$. Results are shown for $(\bullet)$ MRI measurements, $(\boldsymbol{\Delta})$ simulations with the revised Gibilaro drag model, and $(\boldsymbol{\nabla})$ simulations using the EMMS drag model. 
(a)

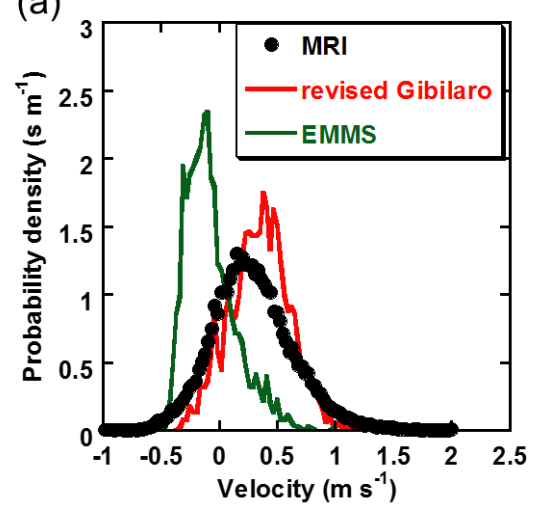

(b)

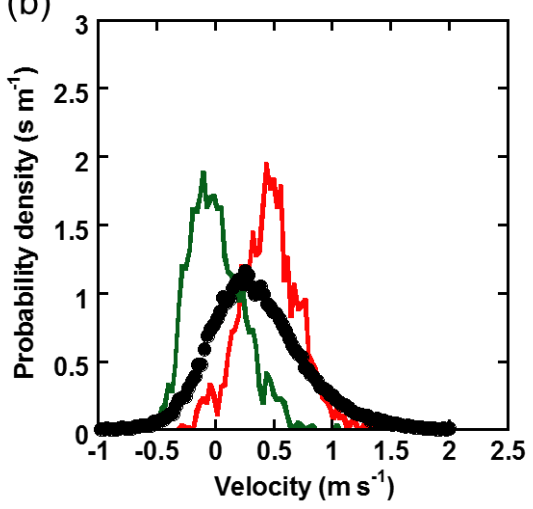

(c)

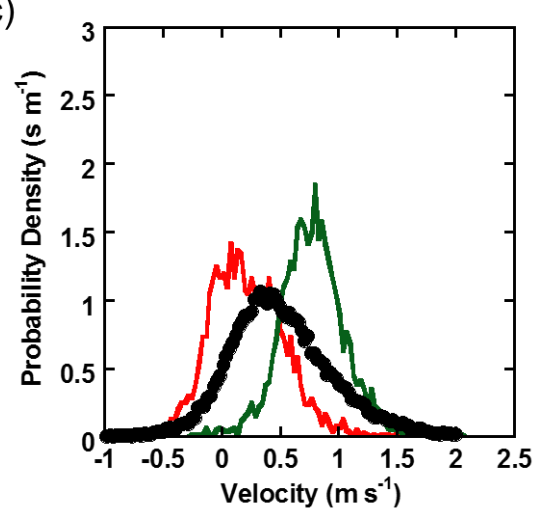

Figure 8 Comparison of probability distribution of the average solids velocity obtained from experiments and simulations at a height of $50 \mathrm{~mm}$ above the distributor for a fluidised bed with a settled bed height of $120 \mathrm{~mm}$. The superficial gas velocities considered were $U_{g}=0.25,0.35$, $0.45 \mathrm{~m} / \mathrm{s}$. Results are shown for (a) MRI measurements, (b) simulations using the revised Gibilaro drag model, and (c) simulations using the EMMS drag model. 

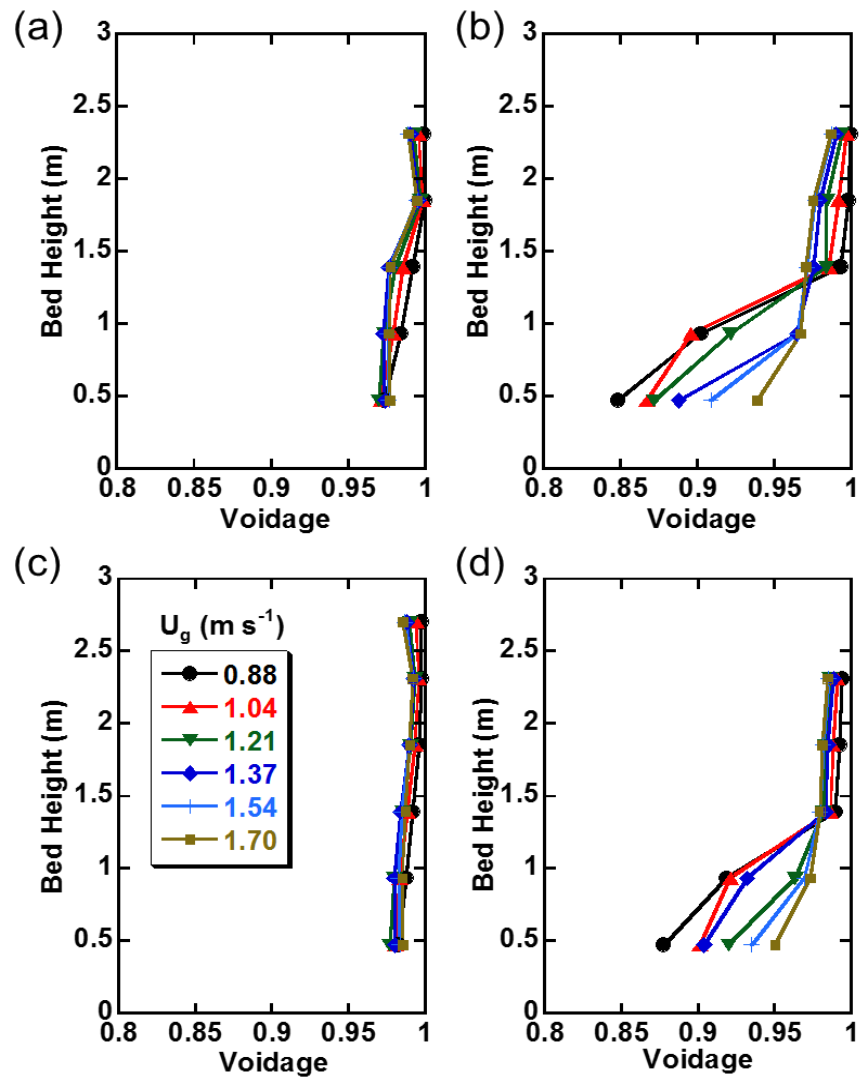

Figure 9 Axial voidage profile obtained from (a) ECT measurements for the low inventory case, (b) ECT measurement for the high inventory case, (c) pressure measurement for the low inventory, and (d) pressure measurement for the high inventory case. 
(a)

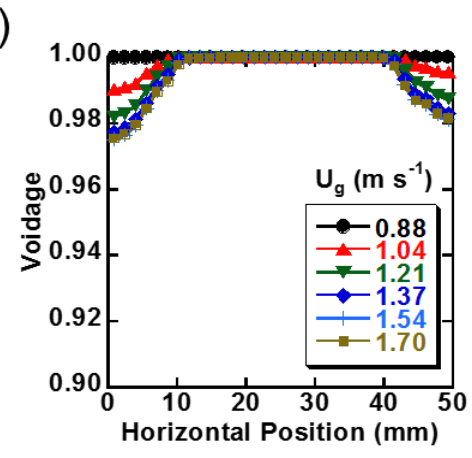

(b)

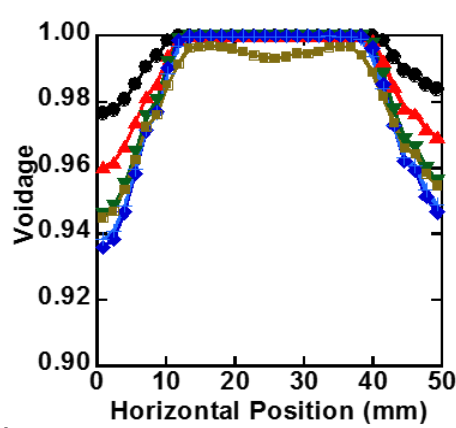

(c)

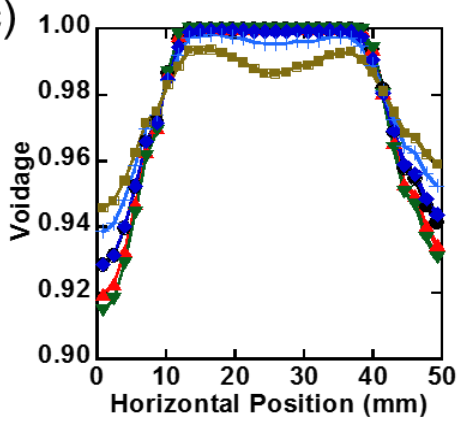

(d)

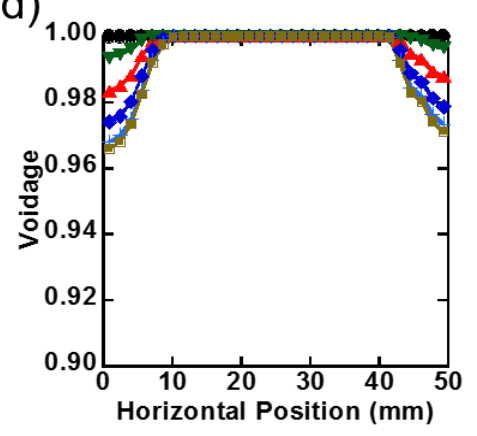

(e)

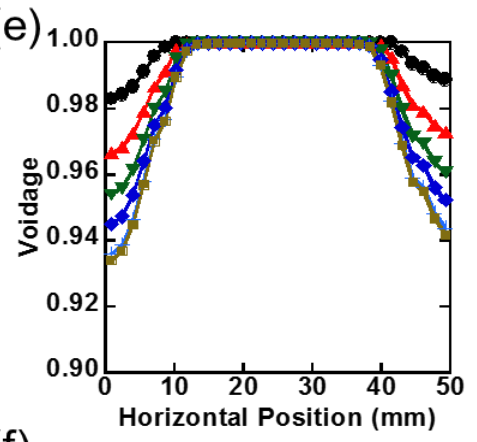

(f)

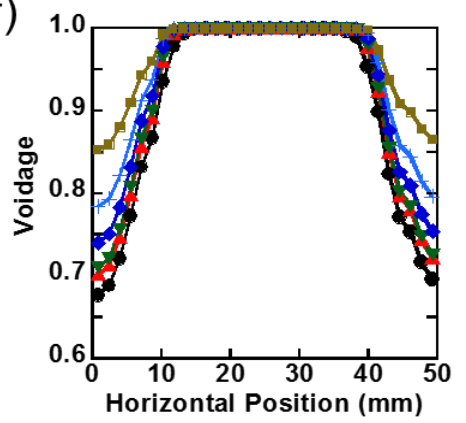

Figure 10 Voidage distribution obtained from a profile through the centre of the riser for $(a-c)$ the low inventory and (d-f) the high inventory cases. Profiles are shown at heights of (a) and (d) $2.315 \mathrm{~m}$, (b) and (e) $1.395 \mathrm{~m}$, and (c) and (f) $0.475 \mathrm{~m}$. 

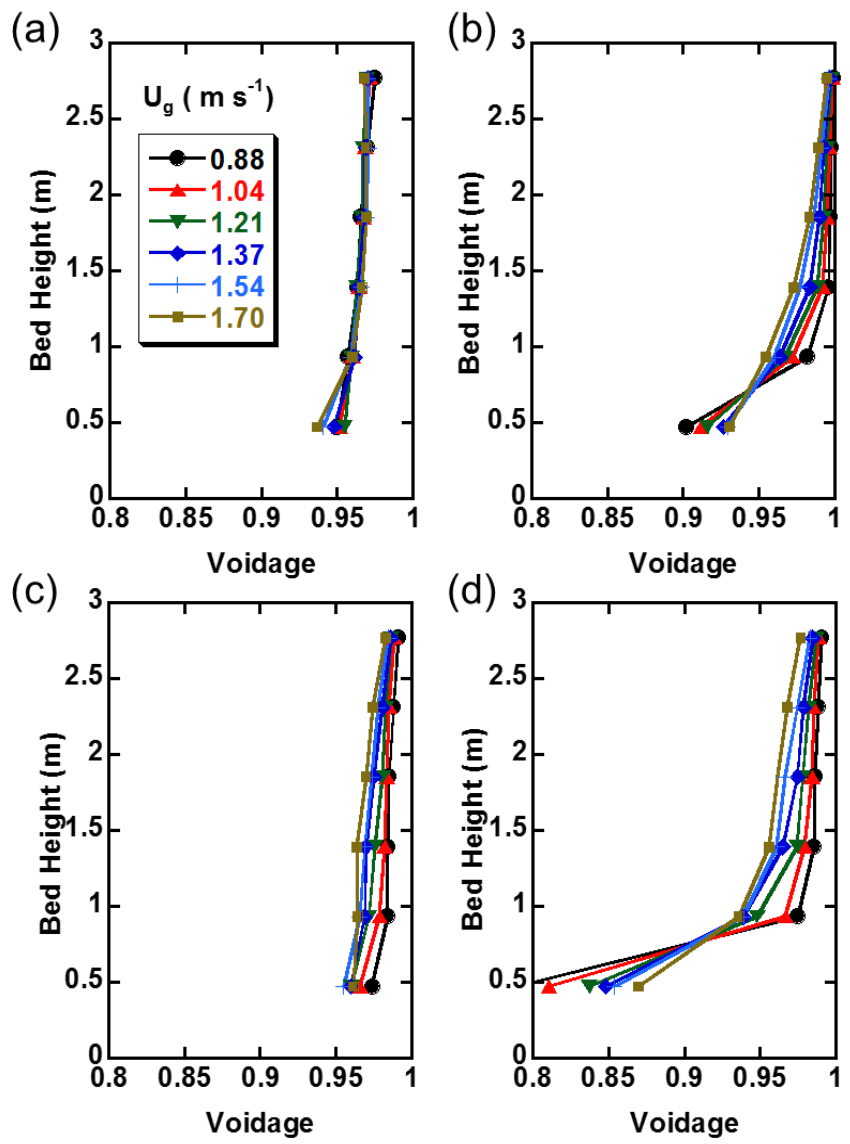

Figure 11 Axial voidage profiles along the riser obtained from TFM simulations with the low inventory for (a) the Gidaspow drag model, (b) the revised Gibilaro drag model, and (c) the EMMS drag model and (d) the EMMS drag model with the high inventory. 
(a)

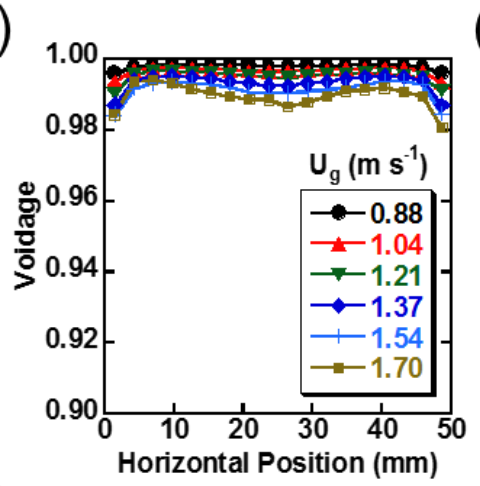

(b)

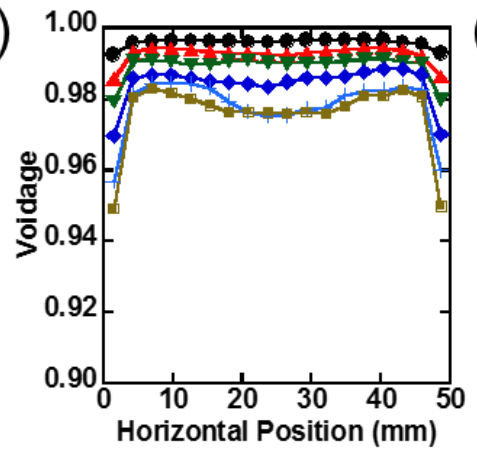

(c)

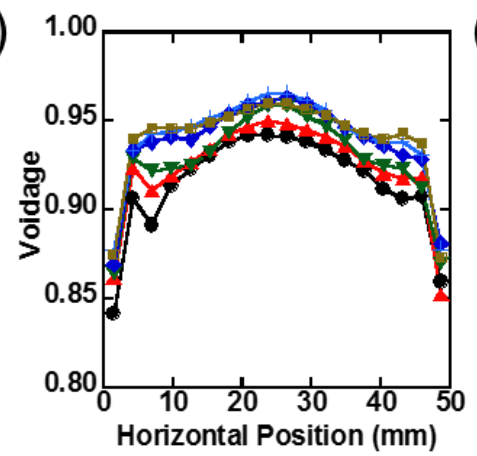

(d)
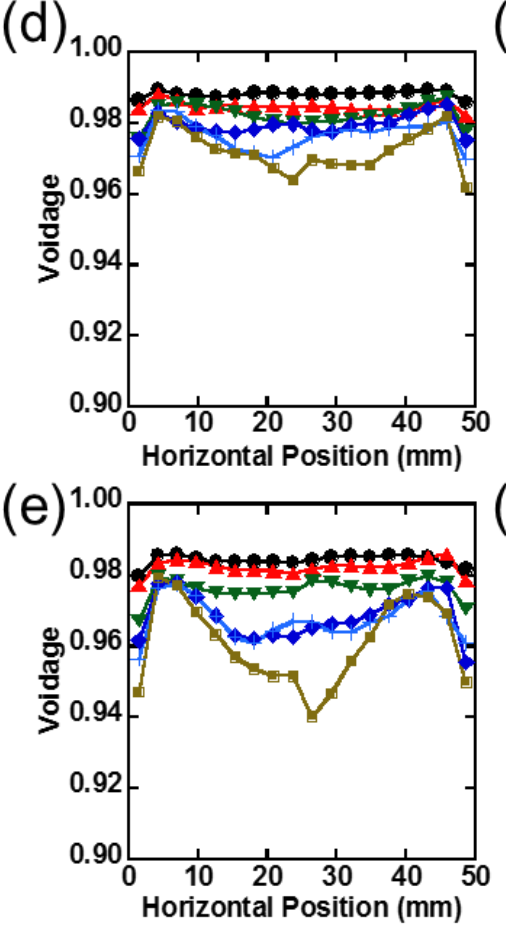

(f)

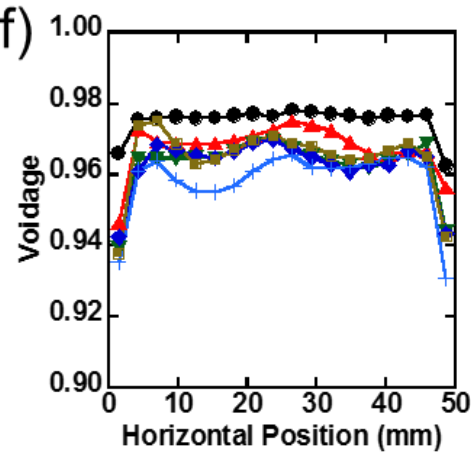

(g)

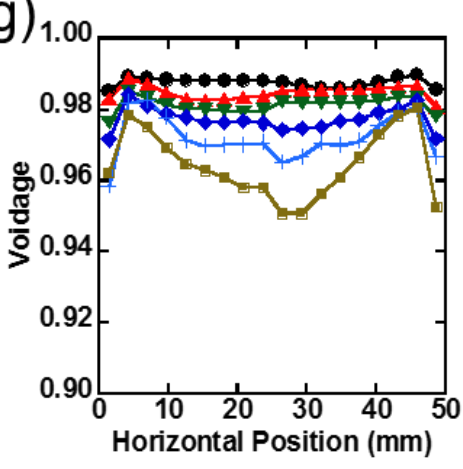

(h)

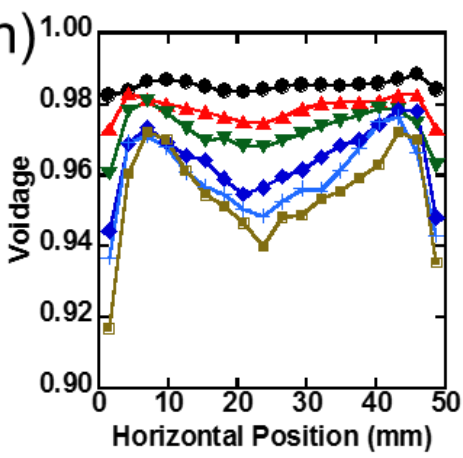

(i)

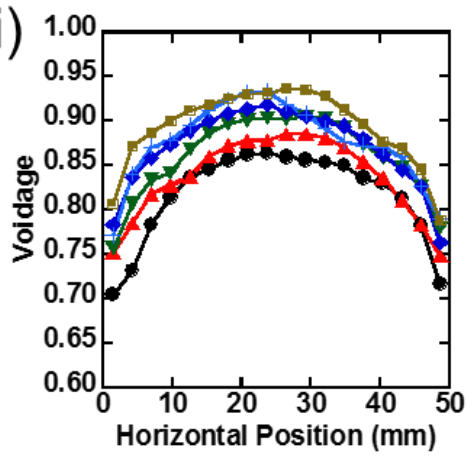

Figure 12 Voidage distributions obtained from profiles through the centre of the riser for (a-f) the low inventory and (g-i) the high inventory cases. Simulations were performed using (a-c) the revised Gibilaro drag model and (d-i) the EMMS drag model. Profiles are shown at heights of (a), (d) and (g) $2.315 \mathrm{~m}$, (b), (e) and (h) $1.395 \mathrm{~m}$, and (c), (f) and (i) $0.475 \mathrm{~m}$. 

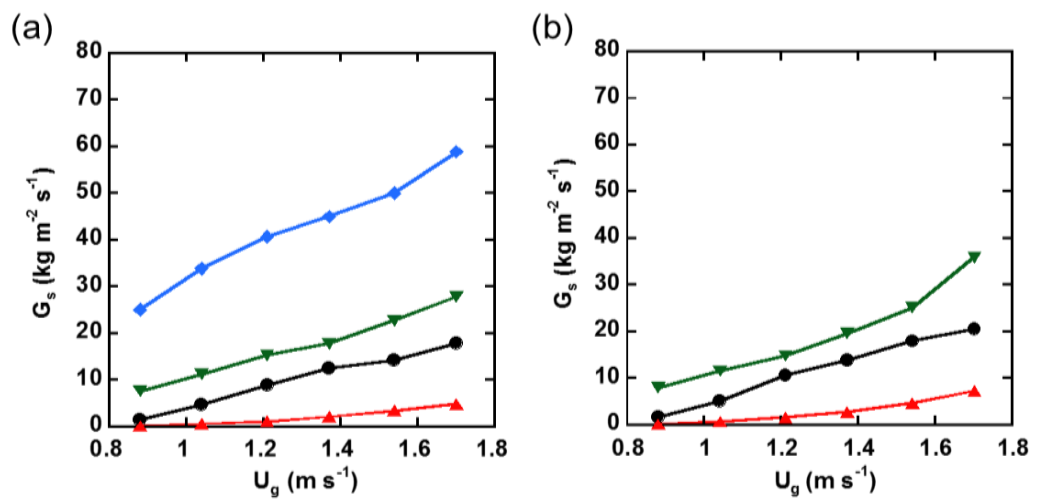

Figure 13 Comparison of solids flux rate obtained from the experiments and simulations for (a) low inventory, and (b) high inventory cases. Results are shown for shown for (•) experimental measurements, $(\diamond)$ simulations with the traditional Gidaspow drag model, $(\boldsymbol{\Delta})$ simulations with the revised Gibilaro drag model, and $(\nabla)$ simulations using the EMMS drag model 
Table 1 Physical properties of materials and simulation parameters

\begin{tabular}{|c|c|c|}
\hline Simulation conditions & Dense bed & Circulating bed \\
\hline Dimensions (diameter $\times$ height) $(\mathrm{m})$ & $0.05 \times 0.6$ & $0.05 \times 2.83$ \\
\hline Temperature $(\mathrm{K})$ & 297 & 297 \\
\hline Pressure $(\mathrm{Pa})$ & 101325 & 101325 \\
\hline Gas density, $\rho_{g}\left(\mathrm{~kg} / \mathrm{m}^{3}\right)$ & 1.17 & 1.2 \\
\hline Gas viscosity, $\mu_{g}(\mathrm{Pas})$ & $1.75 \times 10^{-5}$ & $1.8 \times 10^{-5}$ \\
\hline Solids density $\rho_{s}\left(\mathrm{~kg} / \mathrm{m}^{3}\right)$ & 1530 & 1530 \\
\hline $\begin{array}{l}\text { Minimum fluidisation velocity } \\
U_{\mathrm{mf}}(\mathrm{m} / \mathrm{s})\end{array}$ & 0.002 & 0.002 \\
\hline Particle diameter, $d_{p}(\mu \mathrm{m})$ & 63 & 63 \\
\hline Superficial gas velocity, $U(\mathrm{~m} / \mathrm{s})$ & $0.25,0.35,0.45$ & $\begin{array}{l}0.88,1.04,1.21,1.37 \\
1.54,1.70\end{array}$ \\
\hline Gas voidage at maximum packing & 0.39 & 0.39 \\
\hline Initial bed height (m) & 0.1494 & low inventory \\
\hline & & high inventory $\quad 0.34$ \\
\hline Initial gas velocity in bed $(\mathrm{m} / \mathrm{s})$ & 0.0024 & 0.04 \\
\hline Initial gas voidage in bed & 0.51 & 0.6 \\
\hline \multicolumn{3}{|l|}{ Simulation method } \\
\hline Spatial discretization & $\begin{array}{l}\text { Second-order TVD } \\
\text { with Minmod }\end{array}$ & $\begin{array}{l}\text { Second-order TVD } \\
\text { with Minmod }\end{array}$ \\
\hline Coefficient of restitution & 0.9 & 0.9 \\
\hline $\begin{array}{l}\text { Under-relaxation factor of solid volume } \\
\text { fraction }\end{array}$ & 0.2 & 0.4 \\
\hline Mesh & $10(r) \times 120(z) \times 10(\theta)$ & $9(r) \times 283(z) \times 12(\theta)$ \\
\hline Initial time step (s) & $1 \times 10^{-4}$ & $1 \times 10^{-4}$ \\
\hline Minimum time step (s) & $1 \times 10^{-7}$ & $1 \times 10^{-7}$ \\
\hline Outflow boundary & $\begin{array}{l}\text { Constant pressure } \\
\text { outflow }\end{array}$ & $\begin{array}{l}\text { Constant pressure } \\
\text { outflow }\end{array}$ \\
\hline Wall boundary condition & $\begin{array}{l}\text { solids phase: Johnson- } \\
\text { Jackson model } \\
\text { (specularity } 0.6 \text { ), } \\
\text { gas phase: no slip }\end{array}$ & $\begin{array}{l}\text { solids phase: Johnson- } \\
\text { Jackson model } \\
\text { (specularity } 0.6 \text { ), } \\
\text { gas phase: no slip }\end{array}$ \\
\hline
\end{tabular}

